University of Redlands

\title{
Managing Safety Assets Using GIS
}

\author{
A Major Individual Project submitted in partial satisfaction of the requirements \\ for the degree of Master of Science in Geographic Information Systems \\ by \\ Mari Cruz Escarcega \\ Douglas Flewelling, Ph.D., Committee Chair \\ Ruijin Ma, Faculty, Ph.D.
}

December 2014 
Managing Safety Assets Using GIS

Copyright (C) 2014

by

Mari Cruz Escarcega 
The report of Mari Cruz Escarcega is approved.

Ruijin Ma, Ph.D.

Douglas Flewelling, Ph.D., Committee Chair

December 2014 


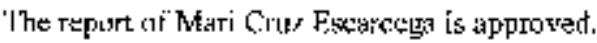
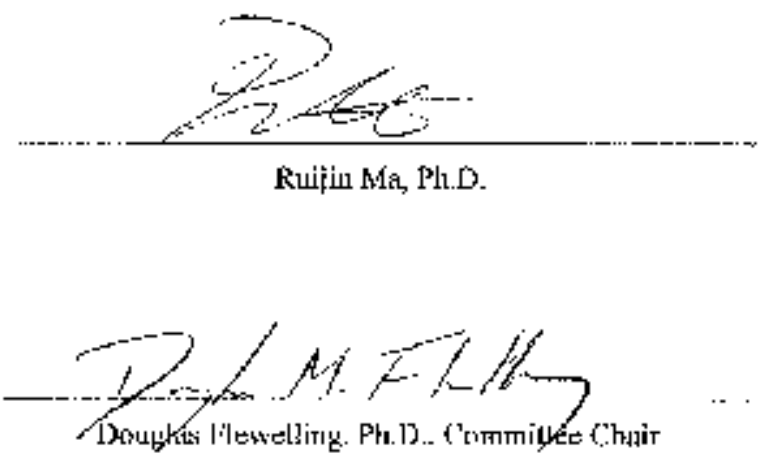

Thenterer 2014 


\section{Acknowledgements}

I would like to thank my lovely daughters Rebecca and Samantha who have given me the courage to follow my dreams. I hope one day they appreciate and understand that hitting Control Alt-and-Delete is sometimes necessary for a new beginning. Marisa, for always listening when I needed someone to talk (thanks cousin), and my friends who make me laugh and provide me with memories that I will always cherish.

I also want to thank the faculty, especially Dr. Douglas Flewelling, who taught me how to think spatially while preserving database integrity. I also would like to thank the staff at the Center of Spatial Studies who provided technical support and assistance with my project implementation.

The experience I gained while enrolled in the program included GIS development using open source software. The help I received from the open source community was beyond my expectations. I was able to connect with Younes Hamdami, in Morocco via Skype, together we set up a server, loaded software, and began programming a GIS protype solution using open source software. Kindness from around the world was priceless.

I leave here with spatial knowledge and great memories of my fellow GIS Cohort who come from all over the world: Bangladesh, Cameroon, Canada, China, Iran, Iraq, Kenya, Libya, Luxemburg, Mongolia, Nigeria, Puerto Rico, Saudi Arabia, Turkestan, and the USA. Getting a group of people united in one place has been a fantastic adventure and a great learning experience, both academically and culturally. It also made great conversation among an international crowd at the University of Redlands. 



\section{Abstract \\ Managing Safety Assets Using GIS}

by

Mari Cruz Escarcega

Buildings on a university campus contain safety assets that require inspection, service, and repair. Knowledge of where equipment is located and the type of equipment are important for safety planning. The current process exists in multiple formats: paper, Excel, Word, and CAD files. Retrieving information where safety equipment is located is time consuming or in the hands of a single individual. By implementing a GIS solution, safety data are available in a single location making it efficient to access data and view where equipment is located when conducting inspections and planning for safety upgrades.

The processes involved organizing a geodatabase, creating map layers, and developing a Web application. A coded value system for subtypes and domain associations provided a visual perspective of room types and their campus usage. In the event of an emergency, facilities management can access safety data in a single location and make informative decisions to surrounding areas. 



\section{Table of Contents}

Chapter 1 - Introduction ................................................................................................. 1

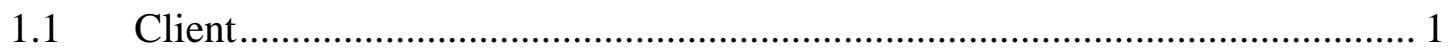

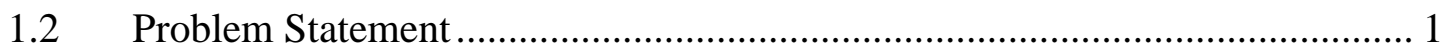

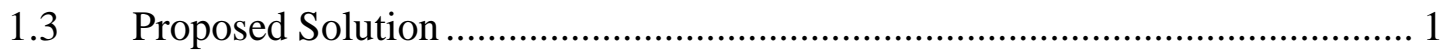

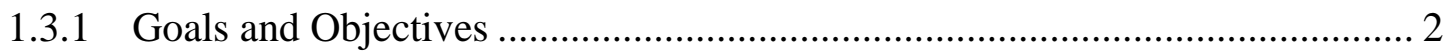

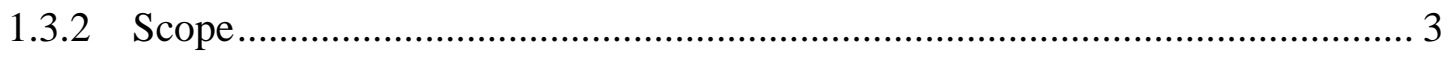

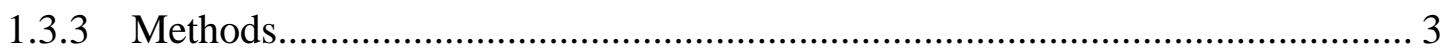

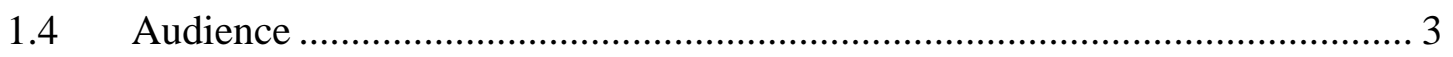

$1.5 \quad$ Overview of the Rest of this Report ....................................................... 3

Chapter 2 - Background and Literature Review ............................................................... 5

2.1 Facilities Management Role and Responsibilities ......................................... 5

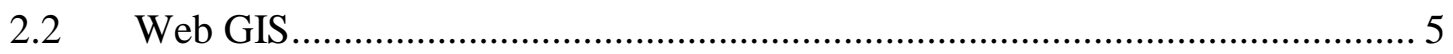

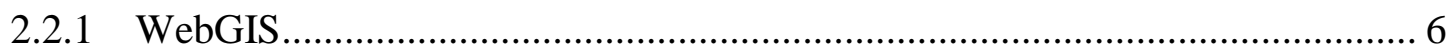

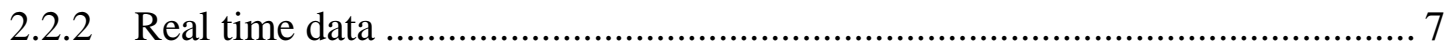

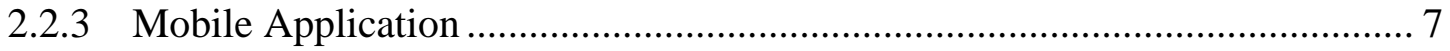

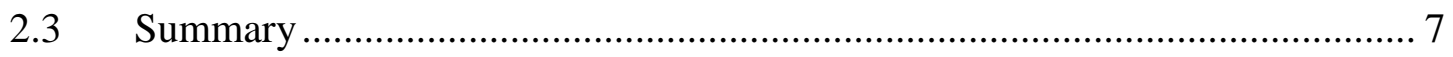

Chapter 3 - Systems Analysis and Design..................................................................... 9

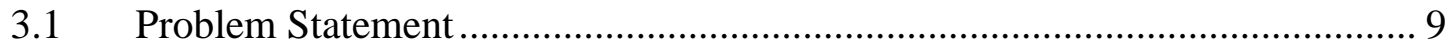

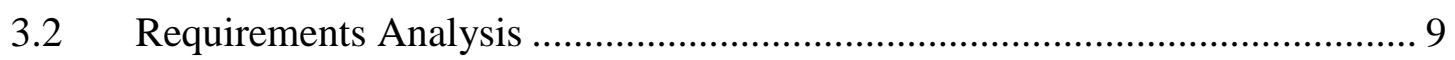

3.2.1 Functional Requirements .................................................................. 9

3.2.2 The Non-Functional Requirements...................................................... 10

3.2.3 Transitional Requirements ....................................................................... 10

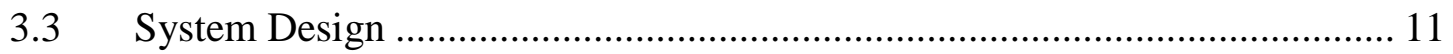

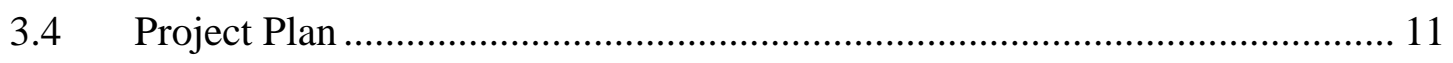

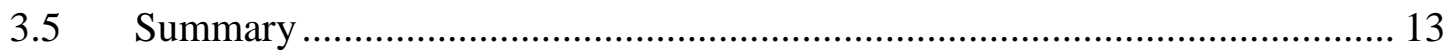

Chapter 4 - Database Design....................................................................................... 15

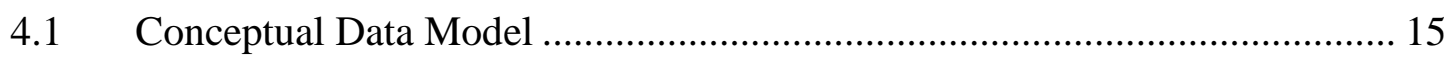

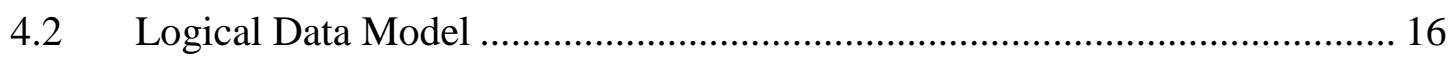

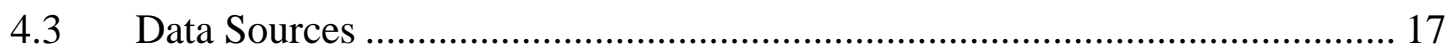

4.4 Data Scrubbing and Loading …………………..................................... 19

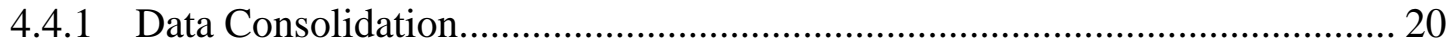

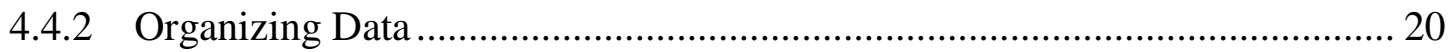

4.4.3 Domains and Subtypes........................................................................... 21 


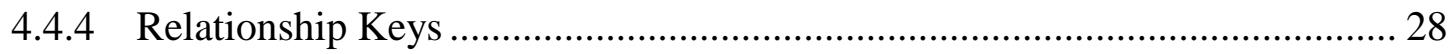

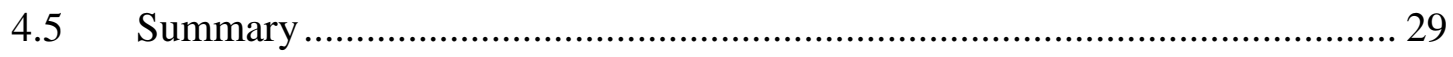

Chapter 5 - Implementation................................................................................................... 31

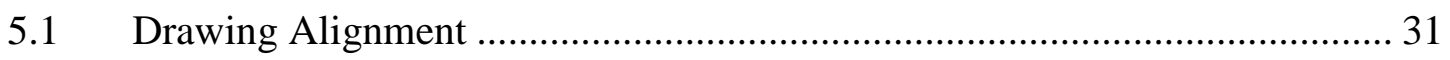

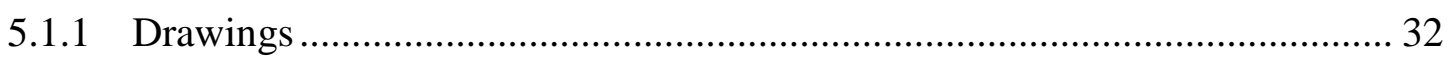

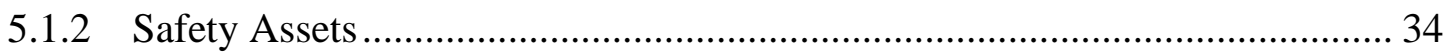

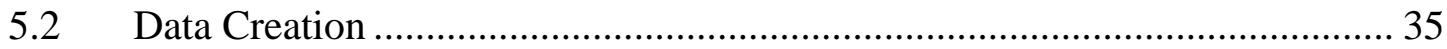

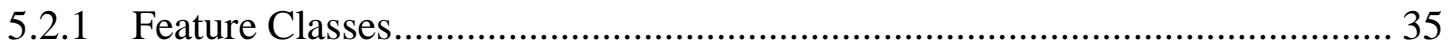

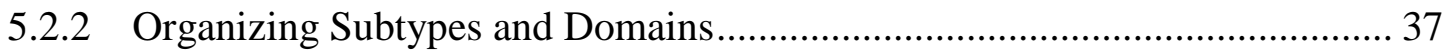

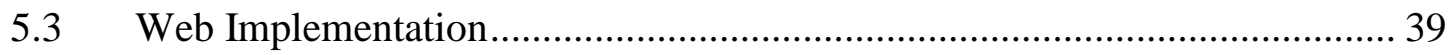

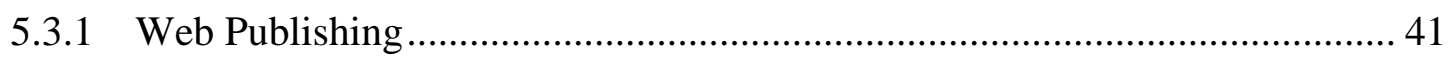

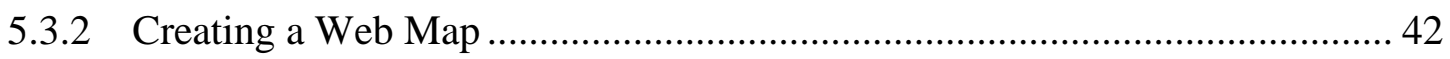

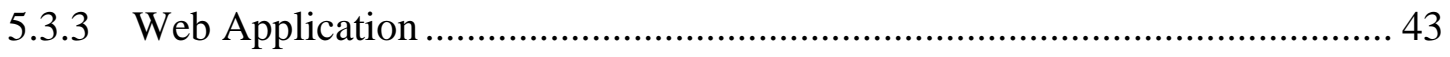

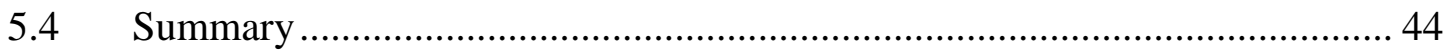

Chapter 6 - Results and Analysis.......................................................................................... 47

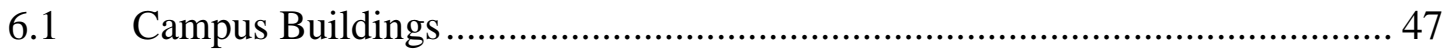

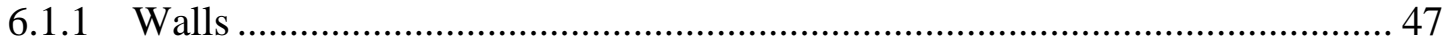

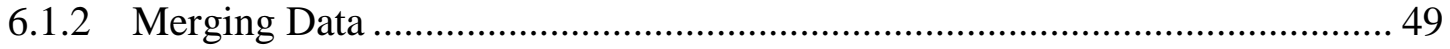

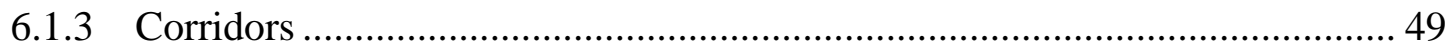

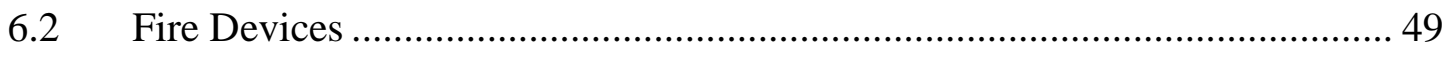

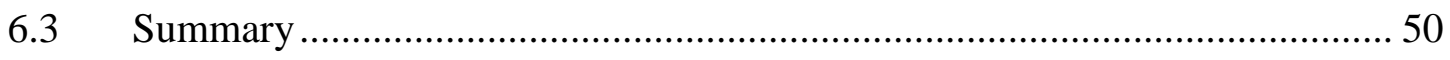

Chapter 7 - Conclusions and Future Work ............................................................ 51

7.1 Summary of Project Deliverables ........................................................... 51

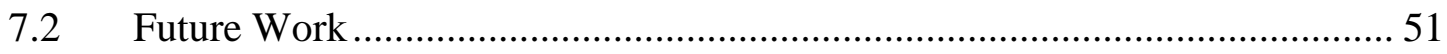

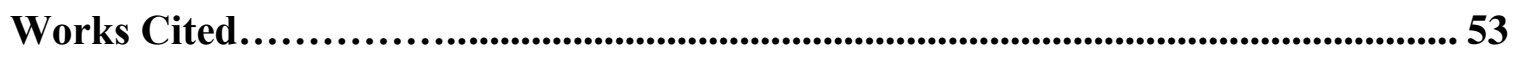

Appendix A. Academic Coded Values ............................................................ 55

Appendix B. Administrative Coded Values............................................................... 56

Appendix C. Other Areas Coded Values ............................................................... 57 


\section{Table of Figures}

Figure 1-1 Appleton Hall and East Hall ...............................................................

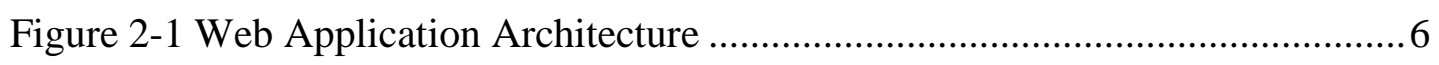

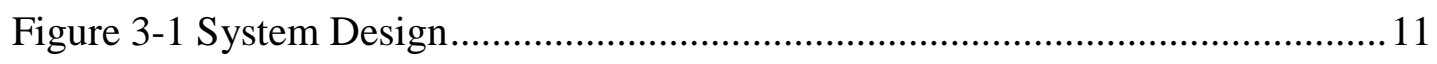

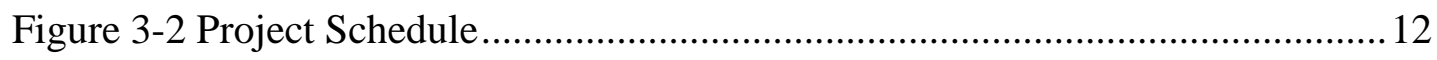

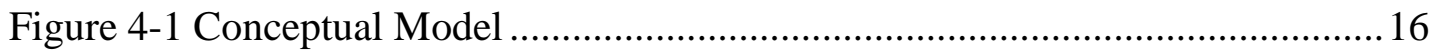

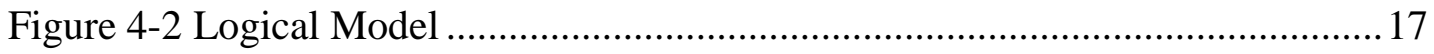

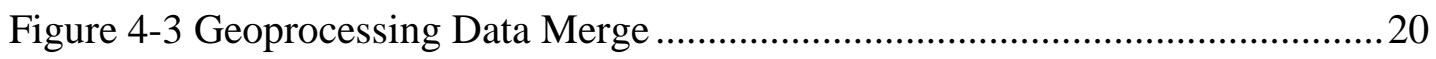

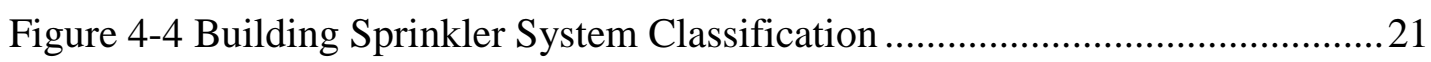

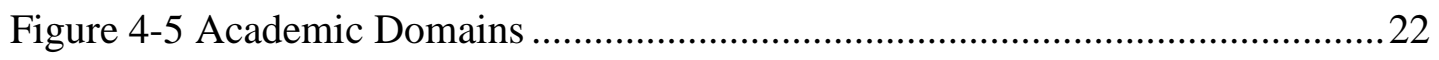

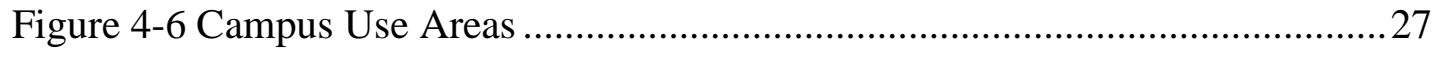

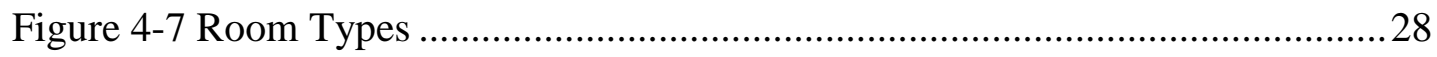

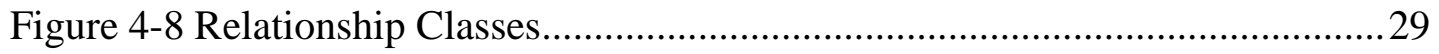

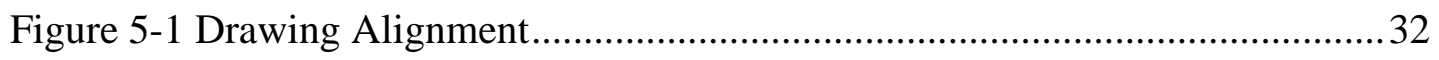

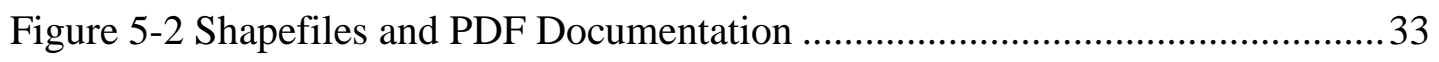

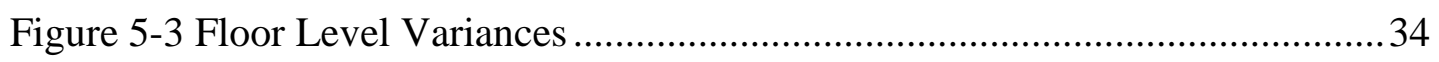

Figure 5-4 Creating Floor Level Feature Classes ……………................................... 35

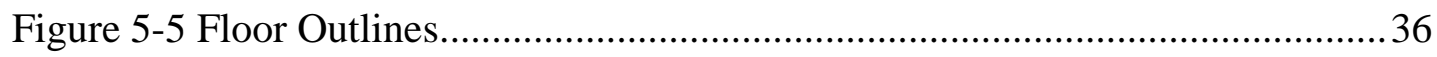

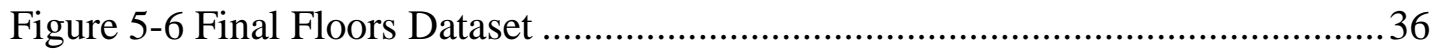

Figure 5-7 Final geodatabase feature classes: Buildings, Floors, and Rooms............37

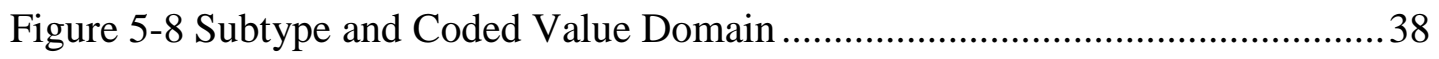

Figure 5-9 Safety Assets Domains........................................................................ 39

Figure 5-10 Building and Floor Level Feature Service ……………........................4

Figure 5-11 Room and Safety Assets map layers ....................................................4

Figure 5-12 Feature Service Layers ................................................................ 41

Figure 5-13 Enabling Feature Layer Properties ................................................... 42

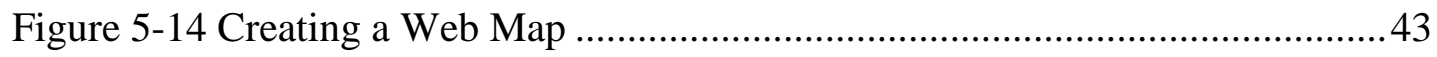

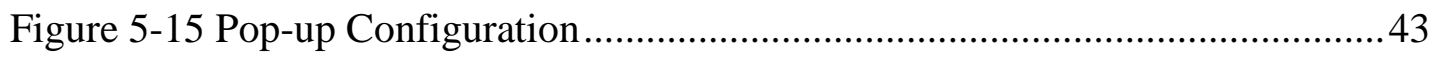

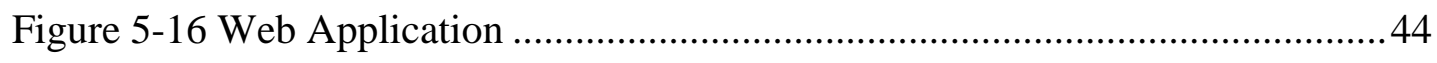

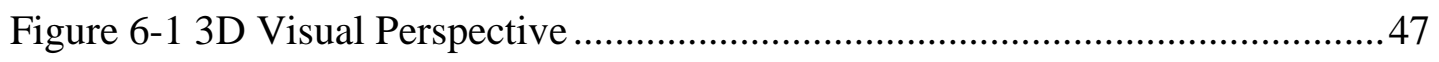

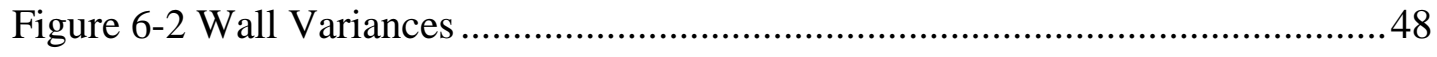

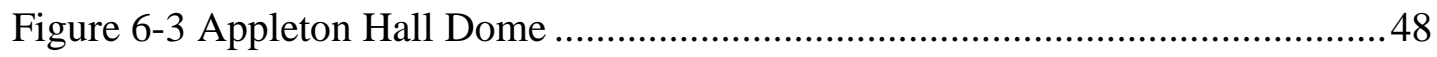

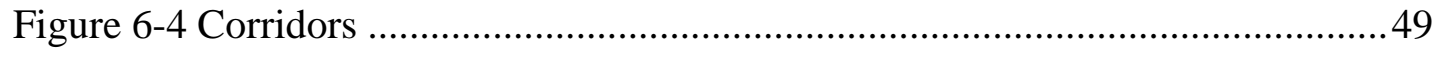





\section{List of Tables}

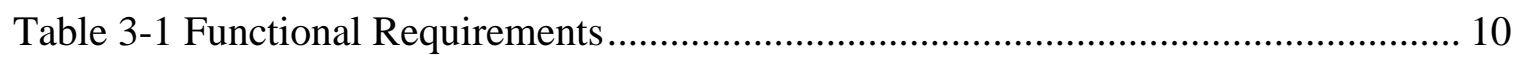

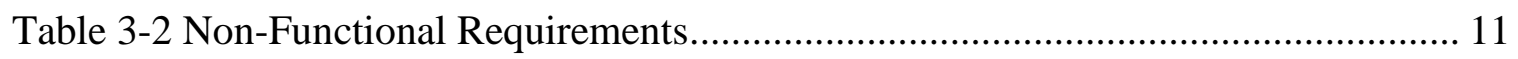

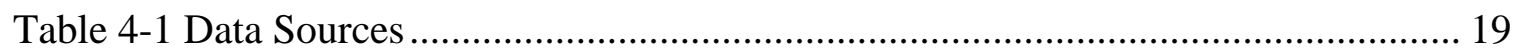

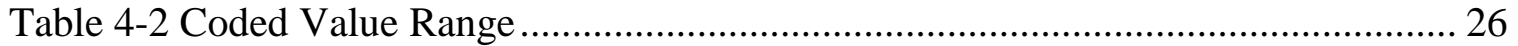





\section{List of Acronyms and Definitions}

$\begin{array}{ll}\text { CAD } & \text { Computer Aided Design } \\ \text { GIS } & \text { Geographic information systems } \\ \text { iOS } & \text { iPhone OS mobile operating system } \\ \text { OOTB } & \text { Out of the box solution } \\ \text { PIV } & \text { Post indicator valve } \\ \text { OS\&Y } & \text { Outside Screw and Yoke } \\ \text { WMS } & \text { Web map service } \\ \text { IFMA } & \text { International Facilities Management Association }\end{array}$





\section{Chapter 1 - Introduction}

Facility management departments are responsible for maintenance of buildings, emergency planning, equipment inventory, new construction, and service inspections. Geospatial information is necessary for planning and decision-making processes in their daily functions.

This chapter explains a proof of concept for a facilities management Web application for fire safety equipment. Section 1.1 and Section 1.2 introduce the client and the need to have spatial records for fire safety equipment. Section 1.3 presents the proposed solution to develop a Web application that enables staff to visualize where fire safety equipment is located and view inspection cycles. Section 1.4 defines the target audience reading this report and Section 1.5 concludes with an overview for the rest of this report.

\subsection{Client}

The client for this project was the University of Redlands Facilities Department. The point of contact was Jennifer Sorenson, Associate Director of Operations. Other support included Nathan Strout, Director of Technology; and Lisa Benvenuti, Spatial Resource Manager, Center for Spatial Studies.

The Facilities Department is responsible for the maintenance of 60 buildings on 160 acres. In 1906, when the University was established, building codes did not require fire sprinkler systems. Today, $47 \%$ of buildings on campus are over 50 years old and $39 \%$ are over 25 years old. Planned capital improvement projects include upgrades to meet the most current building safety codes. This project focused on Appleton Hall built in 2003 and East Hall built in 1999, which represent two different building code scenarios at the time of their construction.

\subsection{Problem Statement}

Buildings on campus contain some form of fire alarm or sprinkler system that require certified technicians to service equipment, document inspections, and make repairs as needed. Existing data lack a coordinate location for the shapes they represent. Coordinate information is necessary to map the environment and data exist in multiple formats: paper, Excel spreadsheets, and Word documents. Retrieving information from varied formats can be time consuming, and data are often in the hands of a single individual. A campus wide map where safety equipment is located does not exist.

\subsection{Proposed Solution}

Having a GIS solution enables facilities managers to view the location of existing safety equipment when conducting inspections and planning for safety upgrades from a single source. The proposed solution was a proof of concept for a Web application to display where safety equipment is located, equipment type, inspection cycles, and condition of the equipment. Development resources included ArcMap 10.1, and an ArcGIS Online 
organization account. Test sites for the project were Appleton Hall and East Hall (Figure 1-1), which represent two typical buildings on the campus: a modern and an older building without one.

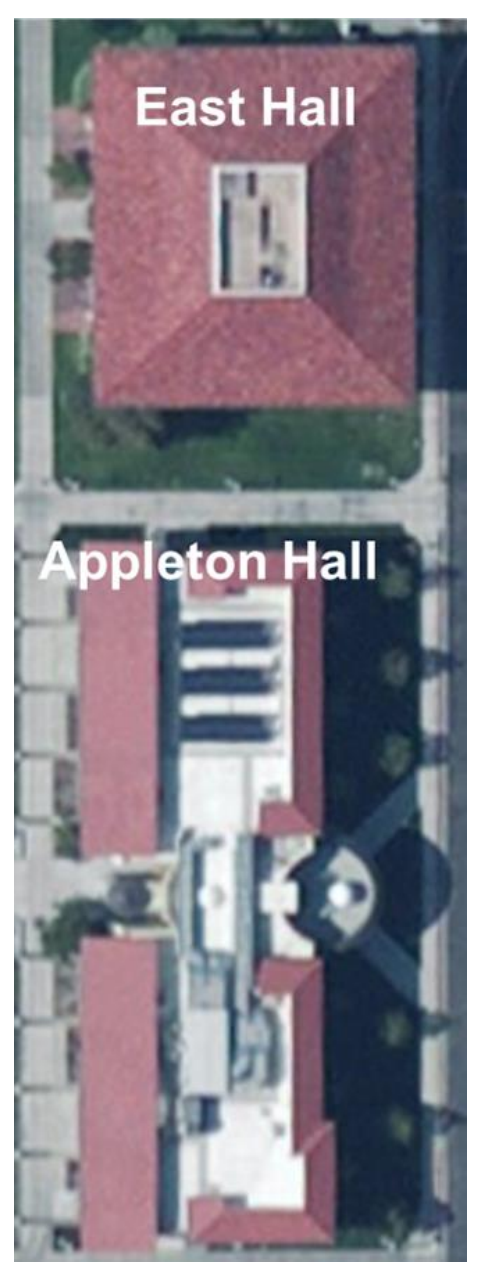

\section{Figure 1-1: Appleton Hall and East Hall}

\subsubsection{Goals and Objectives}

The goal for this project was to identify where safety equipment is located: this included building name, floor level, room number, and room type.

The project objectives were:

- to create map layer where safety equipment are located

- to classify buildings on campus equipped with fire sprinkler systems

- to identify equipment type, condition, and inspection cycle

- to provide a central location where safety crews can access data 


\subsubsection{Scope}

The scope of this project was limited to Appleton Hall and East Hall. It included feature class data sets, data extraction from Excel spreadsheets, creation of a geodatabase, map design, Web development, visual inspection and verification of fire extinguisher data. Field data collection was necessary for features not provided in Excel spreadsheets or client datasets. The processes involved ArcMap 10.1, and an ArcGIS Online organization account.

\subsubsection{Methods}

Methods for this project included Esri software and online services. The process followed a waterfall management approach. The planning phase included discussions with the client to identify project objectives and project deliverables. The research phase included identifying the hardware and software requirements, online services, and data necessary for the completion of the project. Data collection phase involved data extraction, organization, and data creation. The development of the geodatabase involved the design of conceptual and logical models. The implementation phase involved map creation, geodatabase implementation, and Web development.

\subsection{Audience}

The target audience of this report understands facilities management and the importance of incorporating technology to improve efficiency. They work closely with administration and other departments providing support, managing campus events, or maintaining documentation of equipment and safety procedures. They understand the benefits of GIS to simplify equipment safety inspections. The audience also include people who are interested in implementing GIS for their facilities projects and understand geodatabase and Web development.

\subsection{Overview of the Rest of this Report}

The rest of this report consists of the remaining chapters. Chapter 2 provides a literature review of the responsibilities of facilities management and the benefits of using Web GIS to improve workflows. Chapter 3 discusses the systems analyses and design for the project. Chapter 4 includes the logical model, conceptual model and the process involved with organizing the geodatabase. Chapter 5 covers the implementation process and the tools associated to complete this project. Chapter 6 discusses the results and analysis. In closing, Chapter 7 summarizes the project and discusses future work that may be of benefit to the client or perhaps another student. 



\section{Chapter 2 - Background and Literature Review}

The research for this chapter explores the background of facilities management, responsibilities (Section 2.1), use in technology, and planning day-to-day activities. Planning often includes the use of CAD data or paper maps to instruct service maintenance, view building infrastructure repairs, or plan project improvement projects. Implementing geographic information systems (GIS) allows georeferencing of CAD data, and introduces electronic maps to replace paper maps. The literature review includes WebGIS and the benefits of using the technology as a solution for safety inspections (Section 2.2). The chapter concludes with a summary (Section 2.3)

\subsection{Facilities Management Role and Responsibilities}

Facility managers use CAD data, paper maps, or knowledge acquired over time to plan events. Their responsibility is to service and maintain real estate assets for an organization. In an effort to build a GIS application, it is important to comprehend the functions and tasks involved. According to the International Facilities Management Association (2009), facility managers understand the importance of supporting the overall goals, values, and long-term mission objectives of an organization. They have an understanding of budget analysis, customer service, internal and external business practices, training, and technology. Facility department managers are constantly negotiating with vendors for equipment purchases, services, and materials. They facilitate strategies and decision-making processes through analysis scenarios, planning, and exploring alternatives to improve services and productivity. They act on informative decisions and are constantly developing or adopting new efficiency methods.

Facility managers are required to have knowledge of building codes and are often involved in planning for emergency scenarios. Policies and procedures need to be set in place for testing and inspecting equipment used for emergencies. The most common is fire safety, which requires equipment inspection and testing to meet local codes and insurance compliance. Emergency planning requires scheduled fire drills, a visible drawing of the building's fire egress features, and documentation of equipment inspections (Hanford, 2012). In the event of a disaster, facility managers are equipped with knowledge of where things are located and are able to assist emergency personnel in evacuation to ensure the safety of their tenants.

Technology offers facilities management with tools and new methods for collecting data. Reporting information and maintaining current documentation provide meaningful information in the decision-making processes. Proper training is necessary to ensure that the staff understand new technology put in place to improve workflows and productivity (International Facilities Management Association, 2011).

\subsection{Web GIS}

A geographic information system (GIS), is a method that uses a computer system that manages geographic data. The components of GIS include hardware, software, data, processes, people, and networks (Longley, Goodchild, Maguire, \& Rhind, 2011). 
WebGIS is any technology that displays or transmits geographic information using the Internet (Fu \& Sun, 2011, p. 117) for the visualization of map data through a Web browser. The distribution of map data on the Web is introducing new approaches such as Web Services, Web Maps, and mashups of different layers, allowing more flexibility to answer spatial questions on different devices, away from the office and out in the field. It is presenting new workflows through cloud-based services allowing users to access information to create, share, or distribute data (Esri, 2013). The National Institute of Technology and Standards defines cloud computing as follows (Mell \& Grance, 2011, p. 2).

A model for enabling ubiquitous, convenient, on demand network access to a shared pool of configurable computing resources (e.g., networks, servers, storage, applications, and services) that can be rapidly provisioned and released with minimal management effort or service provider interaction.

Figure 2.1 illustrates a typical Web application architecture. It includes a client with loaded software, a geodatabase to store data, and development. Data is organized and transformed for visualization, and published to the cloud available as a Web application or Web Service. Mobile devices equipped with Web browsers are able to view, edit, or publish data directly to the cloud.

\section{Figure 2-1: Web Application Architecture}

At the 2014 Esri User Conference Plenary session, Jack Dangermond discussed the topic of cloud-based services changing GIS. Through cloud-based-services, WebGIS becomes an interconnected platform and centralized location for devices to access information and share geospatial data. It is an emerging trend facilitating open environments, open policies, and open networks. In a cloud-based service, GIS leverages existing infrastructure to build frameworks where people can work on geospatial problems. GIS becomes available in a Web-based environment, organized, shared through web maps and web services available on cloud-based-portals (Dangermond, 2014).

\subsubsection{WebGIS}

Out-of-the-box software, integrated networks, and the Internet make it possible for developers to publish geospatial data in the form of map services to the Web. Web applications require a database to store geographically referenced data to display in the form of a map. The design of a database has a direct impact on the performance of the web application and it is important to ensure the correct projections are set and data are verified prior to publishing map services (Singleton \& Longley, 2010).

Utility companies have embraced Web applications to monitor equipment inventory and field inspection workflows. For example, electric companies generate, transmit, and distribute electricity across a geographic area. Each phase of the process is 
in a different location, with equipment that requires maintenance and inspections on a regular basis.

SSP Innovations offers GIS consulting services, and develops custom software solutions for their energy and utility clients. They implement cloud-based services by utilizing out-of- the box solutions (OOTB) and develop custom applications for iOS or Android devices. Hart Electronic Membership (EMC), a member-owned electric cooperative located in the State of Georgia, implemented a new asset inspection program. Web GIS tools improved their inspection workflows for their utility poles and equipment assets. The process involved creating inspection records, re-projecting their data to Web Mercator, and publishing their data to a cloud-based system. The result was a Web Map application where field crews could collect or update utility equipment, report inspections, and allowing them to use the Web Map on any iOS, Android, Windows tablet, or browser-based machine out in the field. Changes display in real time on the dashboard and on the Web Map (Perry, 2014).

\subsubsection{Real time data}

Cloud-based services enable users to upload, share, and deliver geospatial data in real time. Map information displays a visual analysis of a geographic area. A dashboard displays maps in close to real-time (only a few seconds or minutes delay) as staff collect or share data with other users. Examples of real time data include weather maps providing up to the minute information on weather conditions or local road maps reporting the flow of traffic.

The emergence of mobile and mobile apps allows organizations to see real time changes display data as users upload, access, publish, share, or distribute information across the network.

\subsubsection{Mobile Application}

The ability to access data from any web-browser device transforms the use of mobile devices, increasing the possibilities in mobile data collection and allowing developers to create custom applications for devices on Android and iOS platforms. Points to consider when developing mobile applications include technical specification of the device, cellular connectivity, screen display, keyboard, and their use in an outdoor environment (Fu \& Sun, 2011, p. 126).

The mobile revolution is contributing to the change in data collection and processes. Smartphones and tablets equipped with a web-browser are pocket size computers capable of distributing information.).

\subsection{Summary}

In conclusion, WebGIS offers facility managers a solution to access geospatial data through the Web. Infrastructure becomes available in the form of electronic maps to replace paper maps. Through a Web application or Web Service, facility managers are able to plan, analyze, and make informative decisions any time of the day using Webenabled devices and view data in real time. 



\section{Chapter 3 - Systems Analysis and Design}

This chapter focuses on the system analysis and design in creating the application for this project. Section 3.1 presents the problem statement. Section 3.2 focuses on the functional and non-functional requirements. Section 3.3 covers data collection, architecture design

and software requirements. Section 3.4 is the project plan and Section 3.5 concludes with a summary.

\subsection{Problem Statement}

Buildings on campus contain some form of fire alarm or sprinkler system that require certified technicians to service safety equipment, document inspections, and make repairs as needed. Existing data were not georeferenced and were in multiple formats: paper, PDF, Excel spreadsheets, and Word documents. Retrieving the information from the varied existing formats was time consuming, and the data were often in the hands of a single individual. There was no campus wide map for where safety equipment is located.

\subsection{Requirements Analysis}

The requirement analysis identified the tasks and tools necessary to meet the goals of the client. Analysis for this project included three categories: functional, non-functional, and transitional requirements. The functional requirements describe the behavior of what the system must do. The non-functional requirements involve the physical components used to engineer the behavior of the system. The transitional requirements include the final deliverables to the client.

\subsubsection{Functional Requirements}

The client identified six functional requirements for this project as shown in Table 3.1. The system should classify the locations of safety equipment by building name, building code, floor level, and room number. The system should identify an equipment by type, inspection cycle, and its condition. In building codes, the occupancy classification of a room or its usage determines the safety assets for the location. The application should also classify buildings equipped with a sprinkler system. When the university was founded in 1906, sprinkler systems were not a part of building code requirements. Today sprinkler systems are required for new construction projects. The application included map layers to reference inspection areas and provided an inspection record of last person inspecting equipment and date of last inspection to comply with insurance mandates and local jurisdiction building codes. The geodatabase contained four feature classes, a list of domains, and subtypes providing classification for sprinkler systems, room description, inspection cycle, and condition as a sub type field with a drop down menu selection to the feature class. The domains and subtypes are discussed in more detail in Chapter 4. The four feature classes include Buildings, Floor Level, Rooms, and Safety Assets. 
Table 3-1: Functional Requirements

\begin{tabular}{|l|l|}
\hline Functional Requirements & \multicolumn{1}{|c|}{ Description } \\
\hline $\begin{array}{l}\text { The application should } \\
\text { provide location of safety } \\
\text { equipment. }\end{array}$ & $\begin{array}{l}\text { A definition query in the geodatabase } \\
\text { displays equipment by building name, code, } \\
\text { floor level, room number, and room type. }\end{array}$ \\
\hline $\begin{array}{l}\text { Classify buildings equipped } \\
\text { with sprinkler systems. }\end{array}$ & $\begin{array}{l}\text { Two excel spreadsheets were provided with } \\
\text { building name, building code. This } \\
\text { information is now included in geodatabase. }\end{array}$ \\
\hline $\begin{array}{l}\text { The application should } \\
\text { provide distinction between } \\
\text { equipment types. }\end{array}$ & $\begin{array}{l}\text { Domains were set in the geodatabase and } \\
\text { subtypes assigned in the feature class to } \\
\text { identify equipment types }\end{array}$ \\
\hline $\begin{array}{l}\text { The application should } \\
\text { provide a history of past and } \\
\text { current inspection status. }\end{array}$ & $\begin{array}{l}\text { The attribute table contains a pull down } \\
\text { menu for field staff to enter inspection date } \\
\text { stamp. }\end{array}$ \\
\hline $\begin{array}{l}\text { The application should } \\
\text { allow staff to make edits to } \\
\text { selected fields. }\end{array}$ & Edit and update selected fields. \\
\hline $\begin{array}{l}\text { The application should } \\
\text { include a map layer to } \\
\text { reference inspection area. }\end{array}$ & $\begin{array}{l}\text { Map layers were published as Feature } \\
\text { Service to ArcGIS Online. Floor plans are } \\
\text { included as PDF attachments. }\end{array}$ \\
\hline
\end{tabular}

\subsubsection{The Non-Functional Requirements}

The non-functional requirements included the software, services, and components necessary to build the application (Table 3-2). The software requirements included the installation of ArcMap 10.1 for the creation of map layers and geodatabase. The components included a laptop that supported the software requirements for the installation of ArcMap 10.1. The services included access to an ArcGIS Online organization account to publish map layers as Feature Services and for Web development using a template customized to meet the goals of the project.

\subsubsection{Transitional Requirements}

Transitional requirement included documentation and project delivery. It consisted of map layers, a geodatabase, feature services, Web map, Web application, and a final report of the project. The final report contains a DVD with documentation of the project, metadata, and documentation explaining the numeric coded values used in the geodatabase. The client is responsible for the continuation of data maintenance and Web hosting services upon the delivery of this project. 
Table 3-2: Non-Functional Requirements

\begin{tabular}{|l|l|}
\hline \multicolumn{1}{|c|}{$\begin{array}{c}\text { Non-Functional } \\
\text { Requirements }\end{array}$} & \multicolumn{1}{c|}{ Description } \\
\hline $\begin{array}{l}\text { Provide workstation with } \\
\text { ArcGIS 10.1 installed. }\end{array}$ & $\begin{array}{l}\text { Meet system requirements to install ArcGIS } \\
10.1 \text { to workstation. }\end{array}$ \\
\hline $\begin{array}{l}\text { Use ArcMap 10.1 to create } \\
\text { geospatial data. }\end{array}$ & $\begin{array}{l}\text { ArcMap is software applications used for } \\
\text { creation and transformation of map data in a } \\
\text { visual format. }\end{array}$ \\
\hline $\begin{array}{l}\text { Publish maps to an ArcGIS } \\
\text { Online Organization Account }\end{array}$ & $\begin{array}{l}\text { Cloud based service to share maps on the Web } \\
\text { with staff }\end{array}$ \\
\hline Transitional Requirements & \multicolumn{1}{c|}{ Description } \\
\hline $\begin{array}{l}\text { Provide geodatabase } \\
\text { containing data }\end{array}$ & Data includes 4 feature classes \\
\hline $\begin{array}{l}\text { Provide a web application } \\
\text { identifying buildings with } \\
\text { sprinkler systems. }\end{array}$ & $\begin{array}{l}\text { Web application resides on ArcGIS Online } \\
\text { Organization Account. }\end{array}$ \\
\hline $\begin{array}{l}\text { Present solution to client and } \\
\text { deliver documentation. }\end{array}$ & $\begin{array}{l}\text { Documentation includes metadata and } \\
\text { descriptions to numeric values for domains and } \\
\text { subtypes. }\end{array}$ \\
\hline
\end{tabular}

\subsection{System Design}

The system design included organizing data, designing a geodatabase, map layer creation, and Web application development. Organizing data included extraction from the varied formats for the study area only. Geodatabase design involved the creation of feature classes, subtypes, and domains. Map layer creation consisted of creating map layers for each of the floor levels in a building with safety equipment information. Web development included publishing maps as Feature Services, enabling layers for attachments, enabling editing fields for feature attributes only and Web template configuration. Figure 3.1 illustrates the system development process.

Figure 3-1: System Design

\subsection{Project Plan}

The original project plan was to develop a Web application for data collection using open source software for a facilities project. In July, the project was cancelled due to funding, 
support staff found employment elsewhere, and the project was left without resources to move forward. It was agreed by the faculty to explore another project. In August 2014, the facilities department at the University of Redlands, agreed to participate in a proof of concept to manage safety equipment using GIS.

The project was accelerated to meet the timeline requirements (Figure 3-2) of the GIS program. The project plan included: Requirements Analysis, Geodatabase Development, Map Creation, Web Development, Documentation and Project Delivery.

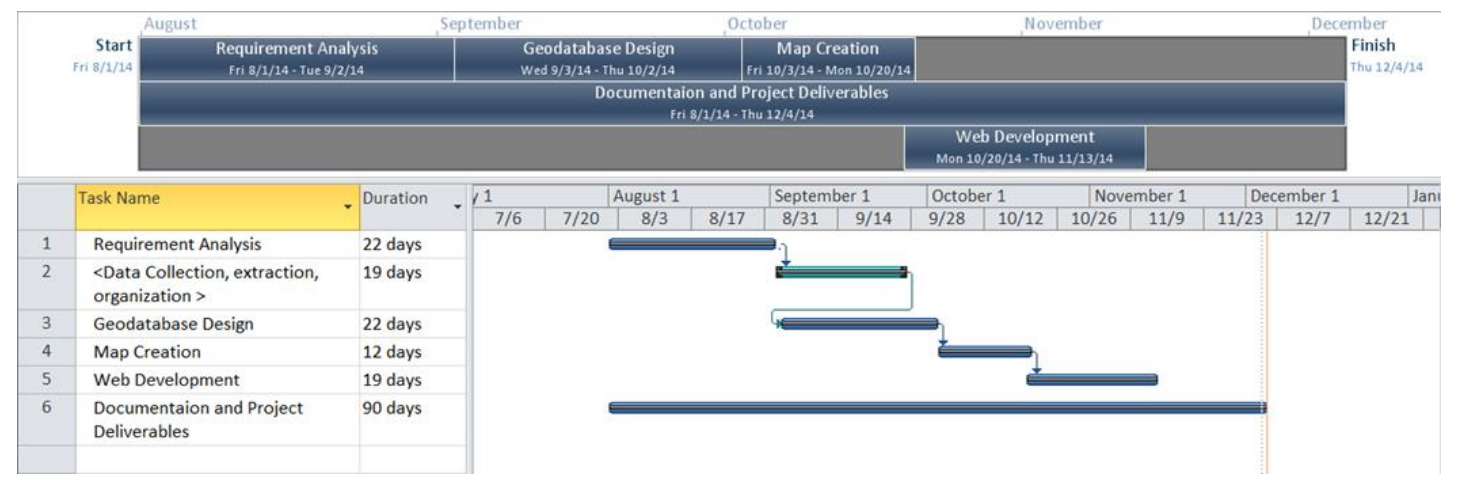

Figure 3-2: Project Schedule

Phase one included requirement analysis, system requirements, and data requirements. Section 4.1 contains the process used to identify and organize data for this project. Phase two involved the design of the geodatabase by establishing a classification system for subtypes to provide room descriptions, inspection cycles, and categorize the condition of safety equipment. Phase three consisted of map creation using ArcGIS 10.1. It included styling, symbology, and publishing layers as Feature Services to an ArcGIS Online Organization account. Phase four includes Web services for the development of a Web application using a Web template available for configuration through an ArcGIS Online organization account.

Strategy meetings were conducted with the client to outline project scope, identify test locations, perform data collection, and determine project deliverables. It was agreed to develop a proof of concept for a Web application that would classify the location of safety equipment by building, floor level, and room type as well as identify equipment by type, condition, and its inspection cycle. The application will classify buildings on campus equipped with sprinkler systems.. Task included map creation, geodatabase development, and Web development.

Development of the geodatabase included the conceptual and logical models. The conceptual model identified the Feature classes necessary to design the database. The logical model included a detail description of each Feature class with subtypes and domains. The process involved data collection, extraction, and data scrubbing. A numeric classification organized data based on inspection cycles, equipment condition, room descriptions, and campus usage. 
Map creation involved producing map layers to represent buildings, floor levels, rooms by floor level and safety assets by floor level. Maps were published as Feature Services to an ArcGIS Online organization account for Web development.

Web development included creating and publishing map layers to an ArcGIS Online organization account as Feature Services. The tasks included defining Web map properties, map styling, pop-up menu configuration, organizing attributes, template structure, and application testing. Four feature services were published to represent each of the data sets: Buildings Layer, Floors Layer, Rooms Layer, and Safety Assets. A final Web map included all of the layers and shared as a Web application. Documentation for this project included a final report, project findings, metadata, map layers, geodatabase, Web Maps, Web Application, DVD, and final project presentation.

\subsection{Summary}

The chapter covered the phases involved in the system design and analysis. A requirement analysis identified non-functional, functional, and technical requirements in the plan design. Having project requirements, processes, task, and deliverables ensures the client requirements in the Project Plan. The next chapter discusses the design of the geodatabase. 



\section{Chapter 4 - Database Design}

This chapter describes the design of the geodatabase and data collection methods. It includes the logical and conceptual models. The conceptual model (Section 4.1) helped determine what feature classes were necessary, together with their attributes. The logical model (Section 4.2) references the conceptual model to develop the geodatabase. Section 4.3 and Section 4.4 cover data sources and collection methods used in the project. Developing the geodatabase required data scrubbing and loading and this process is covered in Section 4.5. The chapter concludes with an overall summary.

\subsection{Conceptual Data Model}

The conceptual model helped to identify feature classes needed in the design of the geodatabase. The conceptual model provided a guideline in the structure of the feature classes, attributes, and tables necessary in the geodatabase. The first process involved gathering data, organizing and analyzing the study areas to determine the feature classes and their attribute tables. Feature classes included Buildings, Floors, Rooms, and Safety Assets. The relationship is as follows. Buildings have attributes fields with a building name, building code, and sprinkler. Floors have levels inside of a Building. Rooms have been assigned numbers and their descriptions have been assigned to Floors inside of a building. Safety Assets have description types and are installed in a Room. A Room has a description type, on a floor level in a building with a name. Safety equipment requires inspections on a given date by a person who holds certification to conduct inspections on that equipment type. Figure 4-1 shows the design of the conceptual model for this project. 


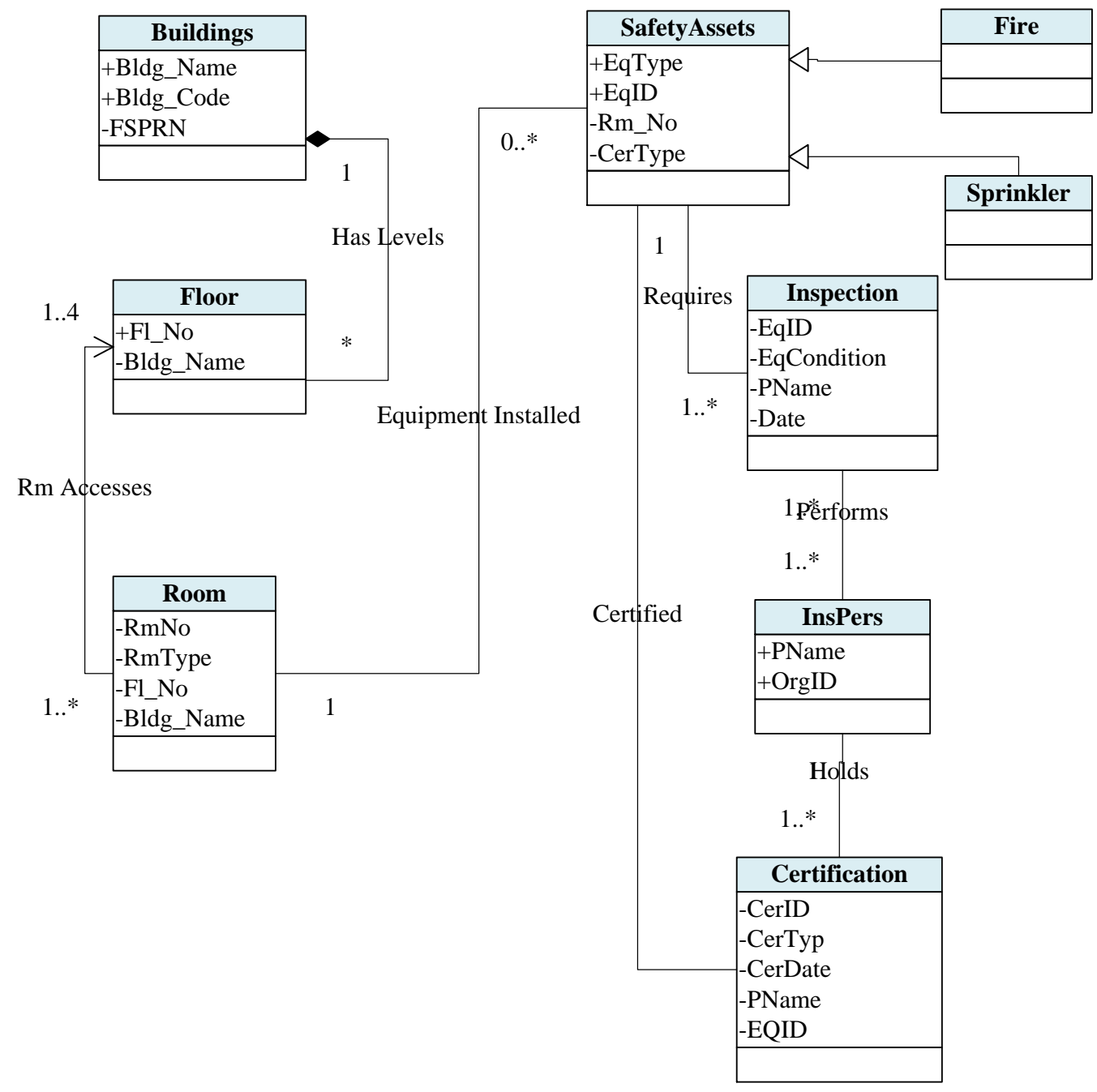

Figure 4-1: Conceptual Model

\subsection{Logical Data Model}

For this project, the database used was a file geodatabase. It followed the structure of the conceptual model. The geodatabase contains four final feature classes: Buildings, Floor, Room, and Safety Assets. The original data provided three field attributes to describe an area of a building. The field attributes included Loc_Area, Descr, and Area_AltNa. Loc_Area field attribute in the original data, made reference to the abbreviated building 
name and room number. The Descr field provided description of the area, and the Area_AltNa field allowed for an alternate name description for the area. The original data did not provide an efficient method to retrieve room data by classification and a uniform system for descriptions did not exist. In addition, managing data for a campus of 60 buildings makes it a challenge to maintain data updates when shape files exist for each floor level per building.

The classifications for identifying campus use were provided by the client as follows: Academic, Administrative, Residential, and Other. Coded value class subtypes were set to a domain in the geodatabase to maintain data consistency. Attribute fields (Figure 4-2) were associated to a defined subtype and linked to a geodatabase domain coded value description.

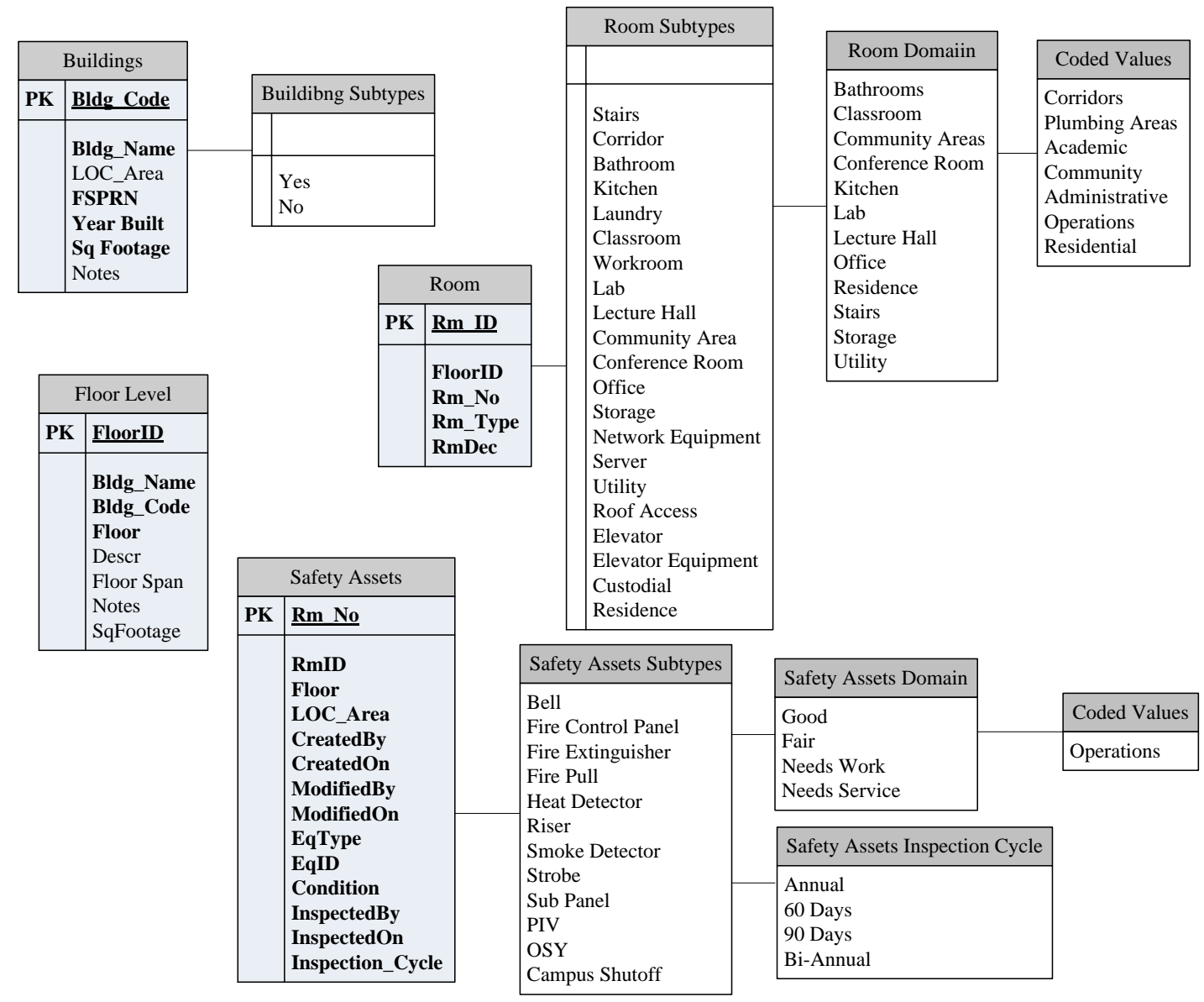

Figure 4-2: Logical Model

\subsection{Data Sources}

Data sources for this project (Table 4-1) included the University of Redlands Facility Department, Center for Spatial Studies at the University of Redlands, visual inspections, and field data collection. The GIS data came in the form of a map package containing a 
geodatabase, four shapefiles, and three tables. The data came projected in NAD 1983 State Plane California V FIPS 0405 Feet, Projection: Lambert Conformal Conic. 
Table 4-1: Data Sources

\begin{tabular}{|l|l|l|l|l|}
\hline Data Set Name & \multicolumn{1}{|c|}{$\begin{array}{c}\text { Data } \\
\text { Type }\end{array}$} & \multicolumn{1}{|c|}{ Data Source } & \multicolumn{1}{|c|}{ Description } & \multicolumn{1}{|c|}{ Data Usage } \\
\hline $\begin{array}{l}\text { Fire } \\
\text { Extinguisher }\end{array}$ & Shapefile & $\begin{array}{l}\text { Center for Spatial } \\
\text { Studies }\end{array}$ & $\begin{array}{l}\text { Collection data of fire } \\
\text { extinguishers }\end{array}$ & $\begin{array}{l}\text { Visual equipment } \\
\text { verification }\end{array}$ \\
\hline $\begin{array}{l}\text { Appleton Hall } \\
\text { 1st \& 2nd Floor }\end{array}$ & Shapefile & $\begin{array}{l}\text { Center for Spatial } \\
\text { Studies }\end{array}$ & $\begin{array}{l}\text { Appleton Hall attribute } \\
\text { data }\end{array}$ & $\begin{array}{l}\text { Merge data to create } \\
\text { feature class }\end{array}$ \\
\hline $\begin{array}{l}\text { East Hall 1st, } \\
\text { 2nd, 3rd, \& 4th } \\
\text { Floor }\end{array}$ & Shapefile & $\begin{array}{l}\text { Center for Spatial } \\
\text { Studies }\end{array}$ & East Hall attribute data & $\begin{array}{l}\text { Merge data to create } \\
\text { feature class }\end{array}$ \\
\hline $\begin{array}{l}\text { Fire Sprinkled } \\
\text { Buildings }\end{array}$ & Word & $\begin{array}{l}\text { Facilities } \\
\text { Department }\end{array}$ & $\begin{array}{l}\text { List of buildings with } \\
\text { sprinkler systems }\end{array}$ & $\begin{array}{l}\text { Referenced data to } \\
\text { create subtype }\end{array}$ \\
\hline $\begin{array}{l}\text { Campus } \\
\text { Monitored Fire } \\
\text { Alarm Systems }\end{array}$ & Excel & $\begin{array}{l}\text { Facilities } \\
\text { Department }\end{array}$ & $\begin{array}{l}\text { List of buildings with } \\
\text { fire alarm systems }\end{array}$ & $\begin{array}{l}\text { Referenced data to } \\
\text { create subtype }\end{array}$ \\
\hline Room Area List & Excel & $\begin{array}{l}\text { Facilities } \\
\text { Department }\end{array}$ & $\begin{array}{l}\text { Description of rooms } \\
\text { on campus }\end{array}$ & $\begin{array}{l}\text { Referenced data to } \\
\text { create subtype and } \\
\text { domain }\end{array}$ \\
\hline $\begin{array}{l}\text { Water flow } \\
\text { Sprinkler }\end{array}$ & Word & $\begin{array}{l}\text { Facilities } \\
\text { Department }\end{array}$ & $\begin{array}{l}\text { List of buildings with } \\
\text { water flow systems }\end{array}$ & $\begin{array}{l}\text { Referenced data to } \\
\text { create subtype }\end{array}$ \\
\hline $\begin{array}{l}\text { Appleton Hall } \\
\text { 1st \& 2nd Floor }\end{array}$ & PDF & $\begin{array}{l}\text { Facilities } \\
\text { Department }\end{array}$ & $\begin{array}{l}\text { Room number and } \\
\text { room description }\end{array}$ & $\begin{array}{l}\text { Referenced data to } \\
\text { create subtype and } \\
\text { domain }\end{array}$ \\
\hline $\begin{array}{l}\text { East Hall 1st } \\
\text { 2nd, 3rd, \& 4th } \\
\text { Floor }\end{array}$ & PDF & $\begin{array}{l}\text { Facilities } \\
\text { Department }\end{array}$ & $\begin{array}{l}\text { Room number and } \\
\text { room description }\end{array}$ & $\begin{array}{l}\text { Referenced data to } \\
\text { create subtype and } \\
\text { domain }\end{array}$ \\
\hline
\end{tabular}

The data compiled for this project included multiple formats: map package, Excel, Word, and PDF documents of building layout with room description. Other collection methods included visual inspections. Only data for Appleton Hall and East Hall were included in the geodatabase. Map package files lacked metadata, a shapefile existed for each building floor level, and most of the attribute files were unpopulated. Excel documents described campus room areas, building information such as building name, code, square footage, year of construction, and sprinkler monitoring services. Word documents contained the list of campus building equipped with sprinkler systems. PDF documents provided information for building floor plan with building name, building code, room number, and area descriptions. Visual inspections included walk through for both buildings and accessible areas to verify the location and type of safety.

\subsection{Data Scrubbing and Loading}

Data scrubbing and loading is the process of organizing data in a suitable format for software upload and use. Organizing the geodatabase consisted of three phases: data consolidation, organizing datasets, and domain association. It was necessary to consolidate the data to maintain a uniform description system, improve data accuracy, 
facilitate maintenance updates, and develop a system to query map layer information based on specified attribute field criteria.

\subsubsection{Data Consolidation}

The first phase combined the data into logical datasets: Building, Floor, Room, and Safety Assets. Using the merge geoprocessing tool, Appleton Hall and East Hall shapefiles were merged to reflect the design of the conceptual model. The output was saved in the new geodatabase by the name Inspections.gdb as a feature class by the name DataMerge. This method maintained more accurate and consistent record keeping. Once merged, it was easier to assign field attributes to each data set according to group association. Figure 4-3 illustrates the geoprocessing tool used in merging the data sets.
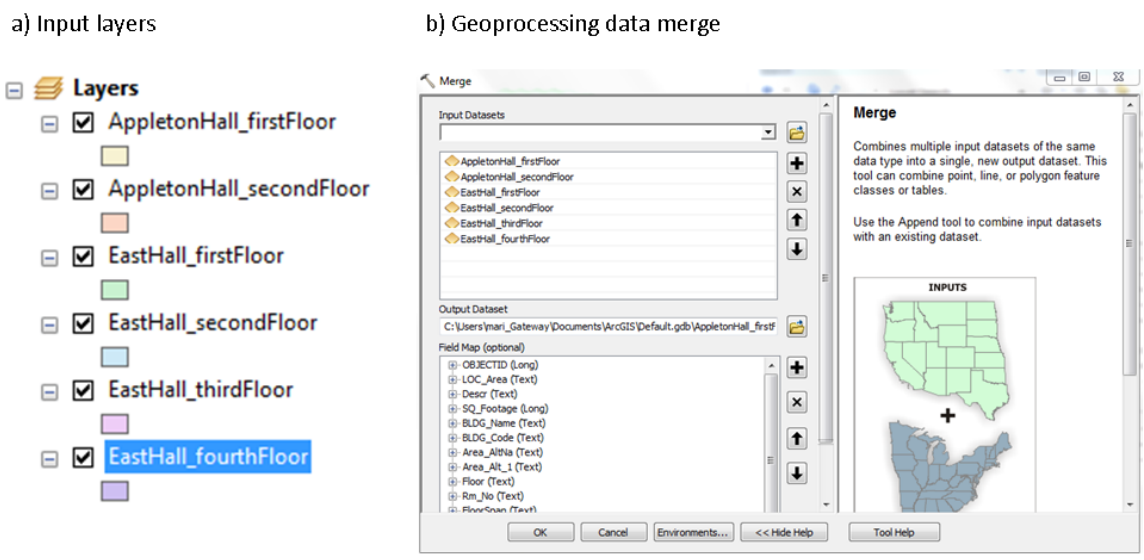

c) Output dataset
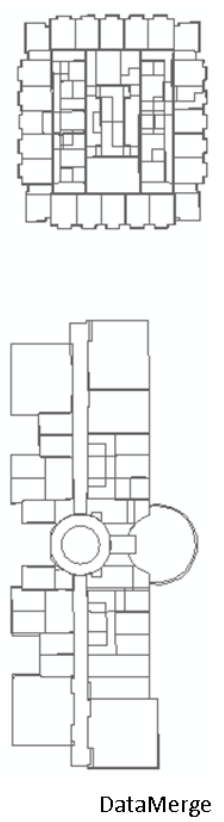

Figure 4-3: Geoprocessing Data Merge

\subsubsection{Organizing Data}

IThe attribute tables were organized with subtype classifications fields linked to a geodatabase domain. The subtype fields were linked to a domain containing defined values for the specified classification through a drop down menu list. Fields were consistent with the client's goal to identify and answer, "Which buildings on campus are equipped with sprinkler systems? Where is equipment located? What type of equipment?" The Buildings feature class contained a subtype field Sprinkler_System, linked to a Boolean domain with a value for "yes or no." Once populated with remaining campus buildings, the user is able to classify buildings on campus equipped with sprinkler systems (Figure 4-4) using a single feature class. The Rooms feature class contained a subtype field for RmType linked to a classification domain for room 
description. The application provides the room type for where safety equipment is located. The SafetyAssets feature class required for each of the safety assets to link to two domains to display inspection and condition values for selected feature attribute.

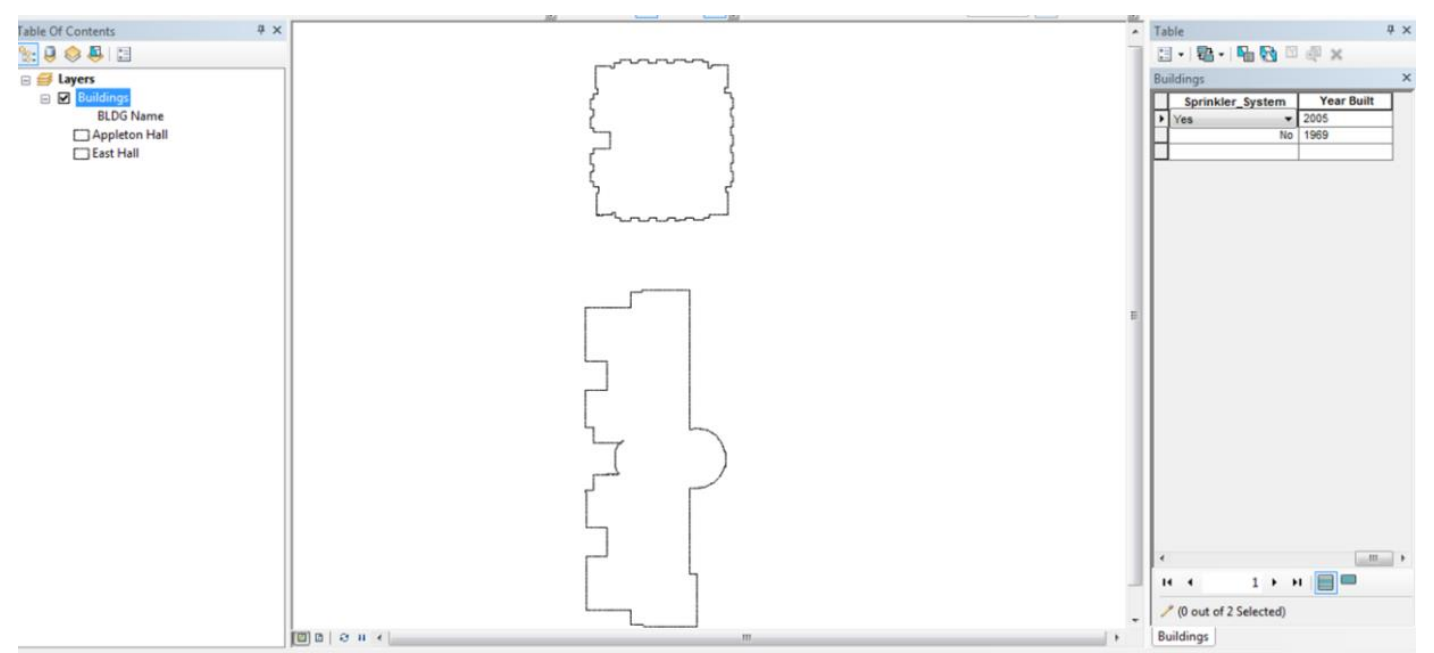

Figure 4-4: Building Sprinkler System Classification

\subsubsection{Domains and Subtypes}

Domains in the geodatabase were set with classification descriptions to populate subtype field attributes with defined value descriptions. The subtypes classify buildings with sprinkler systems, room type, equipment type, inspection cycles, and equipment conditions. The first two digits classify the campus use, the third digit identifies the room type, and the fourth digit provides a room description. Academic areas were assigned a numeric series of 1100. In the feature class these were subtype classifications for classrooms, labs, and lecture halls linked to geodatabase domains. The Classroom domain included a coded value list for three types of classroom in a university campus. The Lab domain included a coded value list for the different types of lab descriptions for the university (Figure 4-5). 

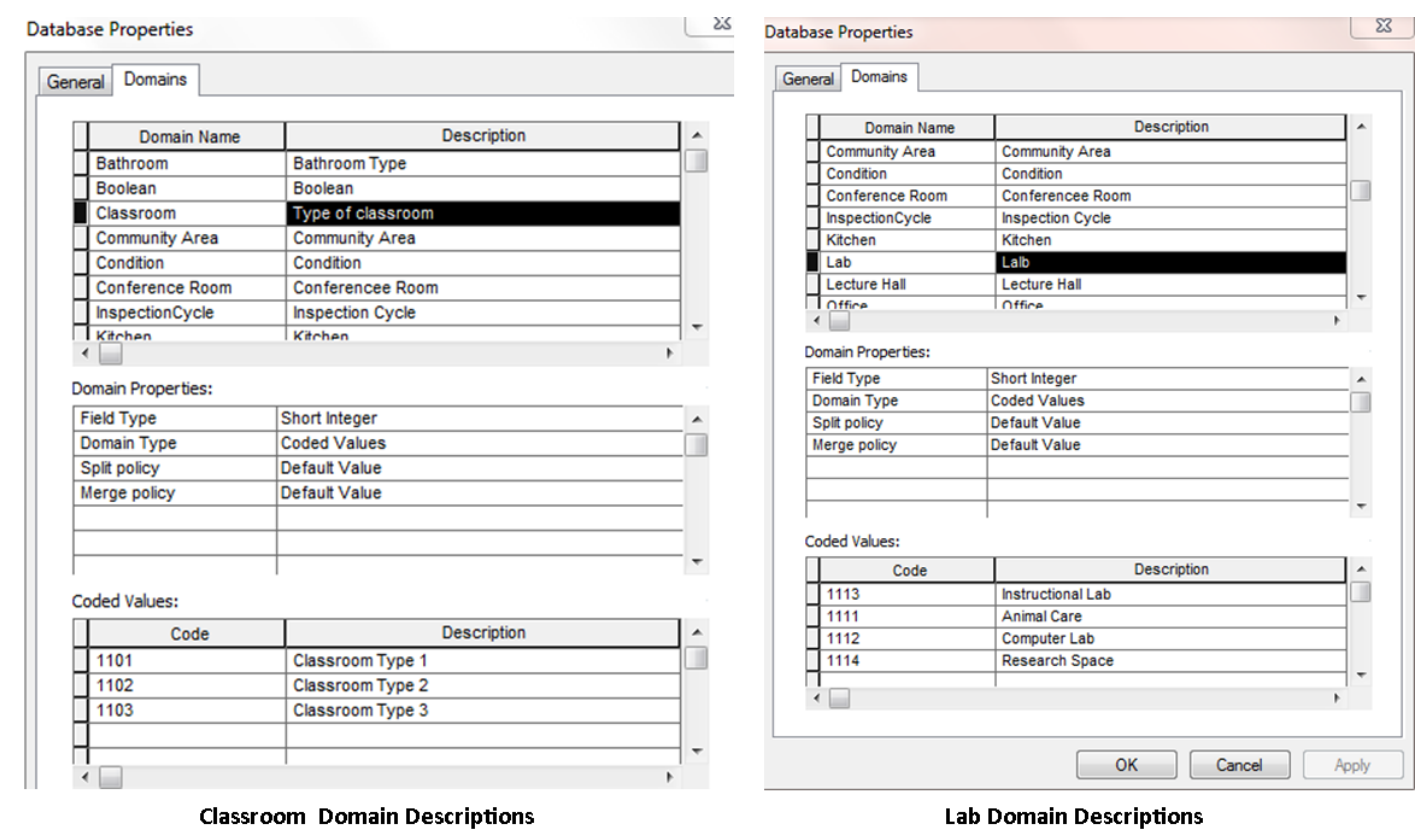

Figure 4-5: Academic Domains

Administrative areas include a coded value range of 1300. Administrative area included office classification for faculty, administrative, and student. Residential areas included a coded value range of 3000 . The client requested residential areas provide room occupancy description as single, double, triple, or quad sleeping capacity.

The Safety Asset dataset contains equipment type information. Fields for this dataset reference the conceptual and logical models. Requirements include an inspection date, equipment type and identification number, inspected by, and condition. Safety Assets coded value range include 1500. An assigned domain to safety equipment allows staff to report the condition of safety equipment using a drop down menu.

Implementing coded values (Table 4-2) provide data consistency, improved accuracy, and a visual perspective of a building campus use (Figure 4-6) and room types (Figure 4-7). Room information is stored in a single feature class for all campus data making it efficient for managing data updates. Coded values with 900 represented corridors and stairways. In the event of an emergency, room data are available in a single location for facilities or emergency responders to make informative decisions to surrounding areas. 
Table 4-2: Coded Value Range

\begin{tabular}{|c|c|l|}
\hline Coded Values & Description & \multicolumn{1}{|c|}{ Domains } \\
\hline 900 & Corridors & Corridors, Stairs \\
\hline $1000-1019$ & Plumbing Areas & Bathroom, Kitchens \\
\hline $1100-1129$ & Academic Areas & Classrooms, Labs, Lecture Halls \\
\hline 1200 & Community Areas & Community Areas \\
\hline $1300-1329$ & Administrative & Conference Rooms, Office \\
\hline $1400-1439$ & Operations & IT and facility access \\
\hline $1500-1519$ & Fire Safety Equipment & Fire Safety Equipment \\
\hline 3000 & Residential & Residence \\
\hline
\end{tabular}




\section{Floor Level 1}

Floor Level 2

Floor Level 3

Floor Level 4
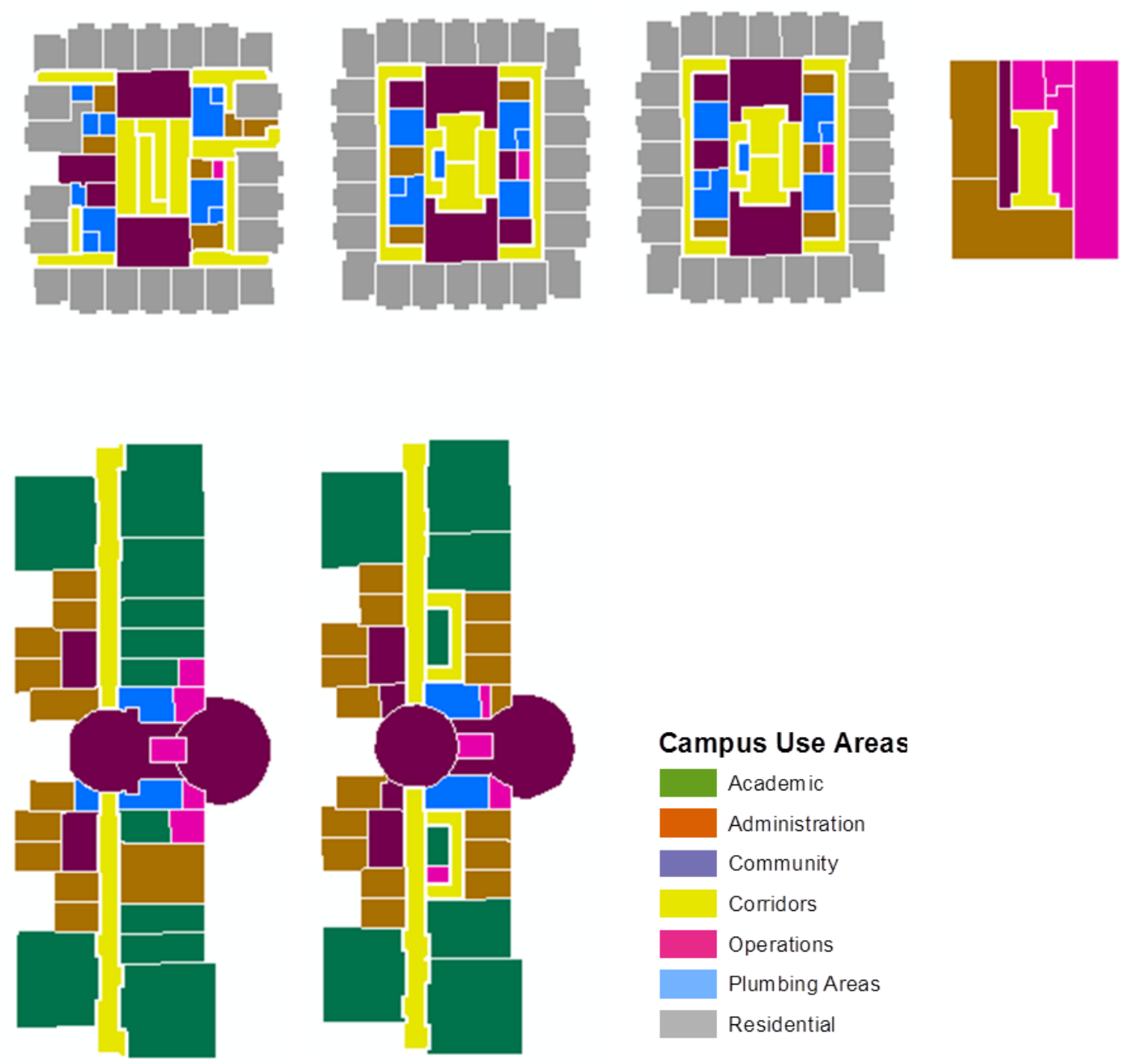

\section{Campus Use Areas}

Academic

Administration

Community

Corridors

Operations

Plumbing Areas

Residential

Figure 4-6: Campus Use Areas 


\section{Room Level 1 Room Level 2 Room Level 3 Room Level 4}

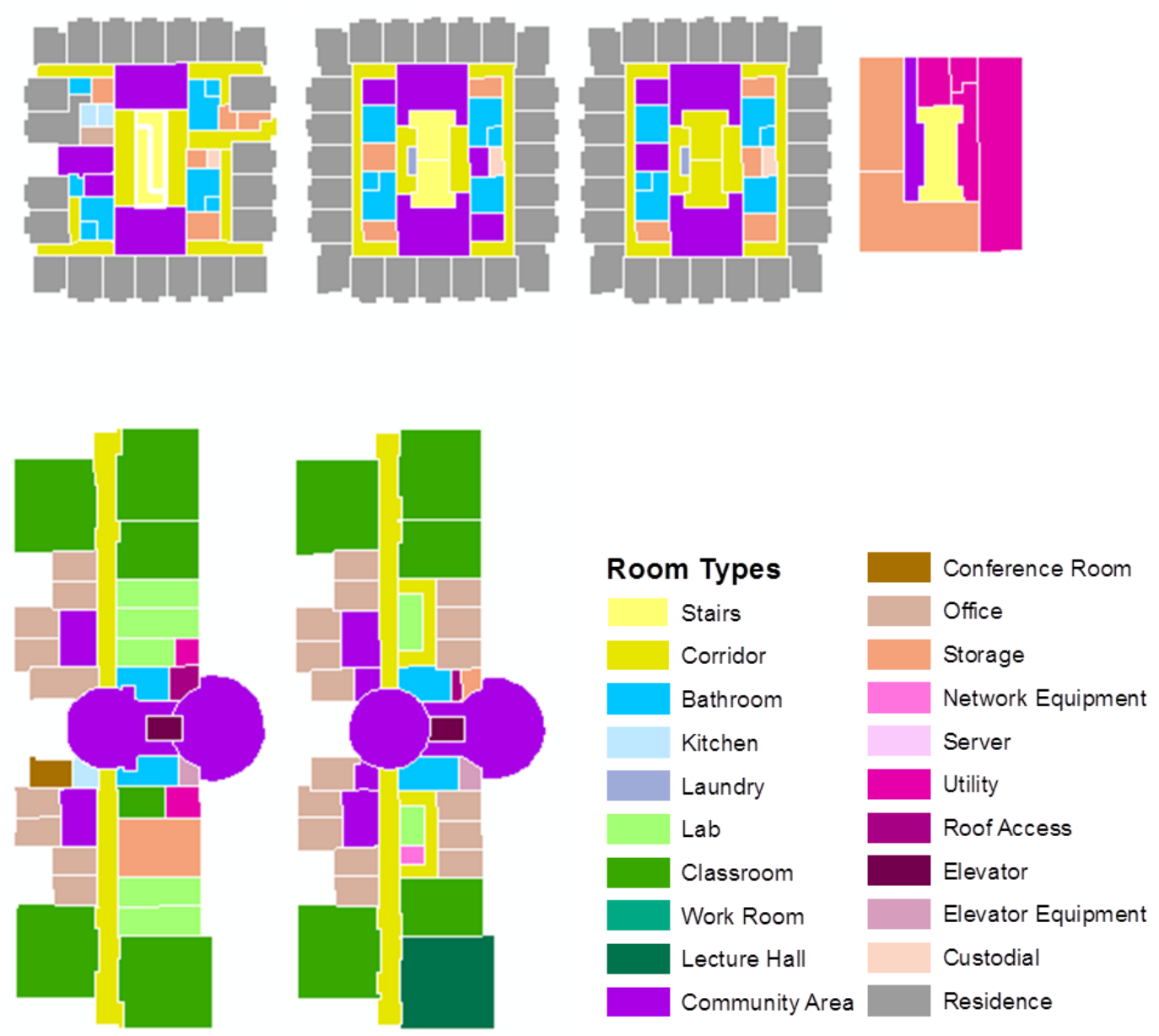

Figure 4-7: Room Types

\subsubsection{Relationship Keys}

Relationship classes maintain integrity and performance in a geodatabase by reducing the duplication of fields in feature classes. Components include a primary and foreign key, establishing cardinality rules, and defining the relationship type. Primary keys establish unique identifiers in a relationship table and are associated as foreign keys in the receiving table. Cardinality rules establish how tables relate to each other through columns and rows. Relationship type specifies the association of the relationship through its link.

The geodatabase for this project contains two relationship classes. The first relationship is between the Buildings and Floor feature classes. The cardinality is a 1-tomany relationship between a single building and the multiple floor levels inside the building. The relationship type is composite. In databases, a composite relationship describes one object attribute with one relationship attribute or one object attribute with many relationships attributes. The primary key in the Buildings feature class is Bldg_Code, the foreign key in the Floor feature class is Bldg_Code.The second 
relationship is between Floors and Rooms feature classes. The cardinality is 1- to- many relationship. A floor level has many relationships to rooms assigned to the floor level. The primary key in the Floors feature class is FloorID. The foreign key in the Rooms feature class is FloorID. Figure 4-8 illustrates the relationship class in the database.

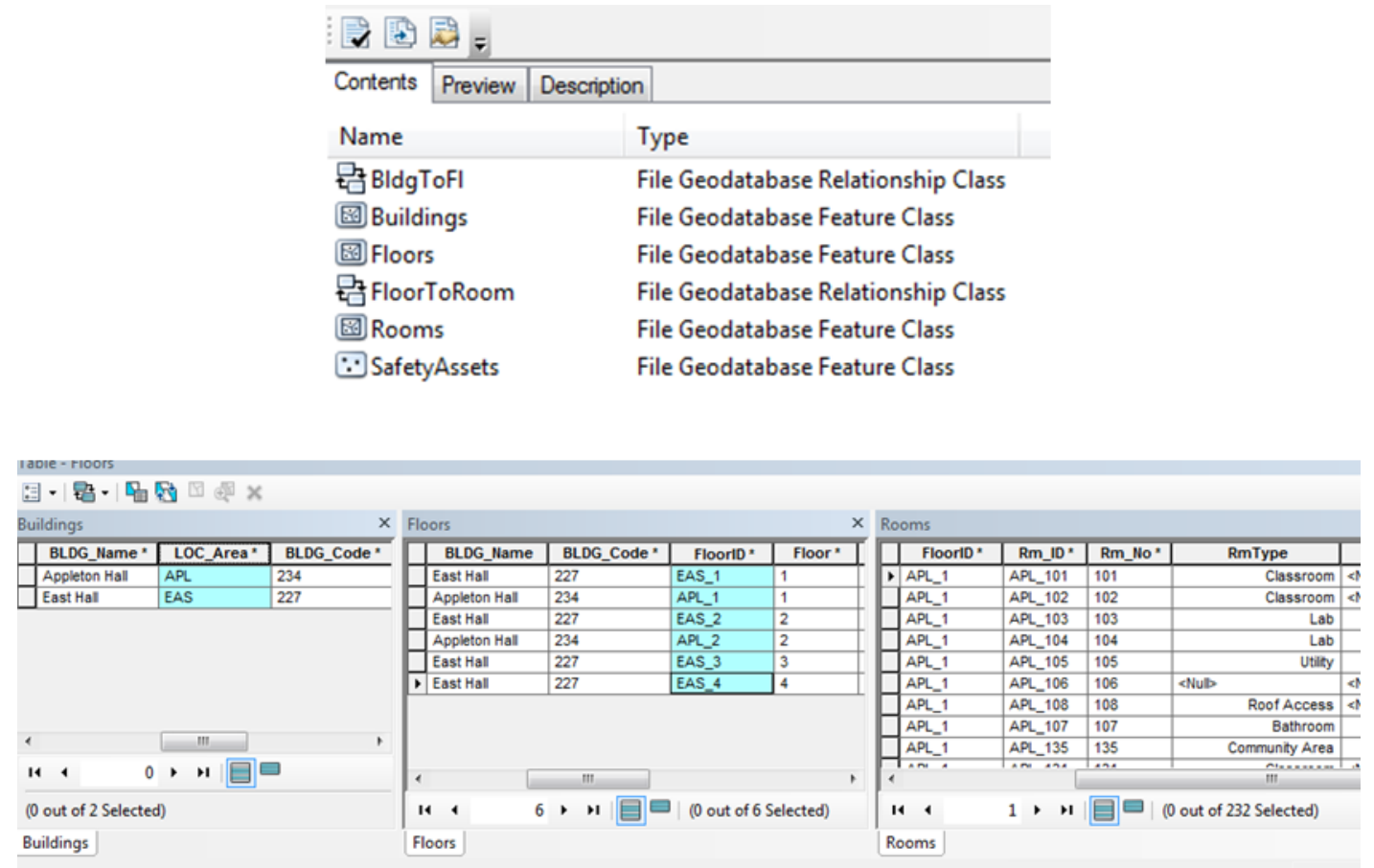

Figure 4-8: Relationship Classes

\subsection{Summary}

This chapter covered the overall design of the geodatabase. The conceptual and logical models aid in establishing data necessary to develop the geodatabase to meet the needs and goals of the client. Knowledge where data come from and the collection methods are helpful when performing data scrubbing, creating fields, and assigning domains. It also facilitates the troubleshooting process when data are loaded to the software. 


\section{Chapter 5 - Implementation}

This chapter covers the implementation of the project. The implementation process included data alignment discrepancies, creating new data, and Web development. Drawing Alignment (Section 5.1) discusses how those discrepancies were resolved. Data Creation (Section 5.2) includes the methods used to create feature classes for the implementation of the project. Web development (Section 5.3) discusses the online services and templates used to develop a Web application. The chapter concludes with summary.

\subsection{Drawing Alignment}

It is unknown what software or imagery were used when the data were created in 2003. Students in an EVST Design Studio created the drawings as part of a class project. In 2006, the data were digitized as a shapefile and georeferenced using USGS ortho imagery. In 2010, it was georeferenced against campus flown aerial imagery. When compiled into the geodatabase for this project (Figure 5-1), the data displayed a shift against ArcGIS Online World Imagery and Topographic basemap layers. The shift was resolved by selecting the map layers, and aligning the drawings for improved consistency to Esri World imagery. 


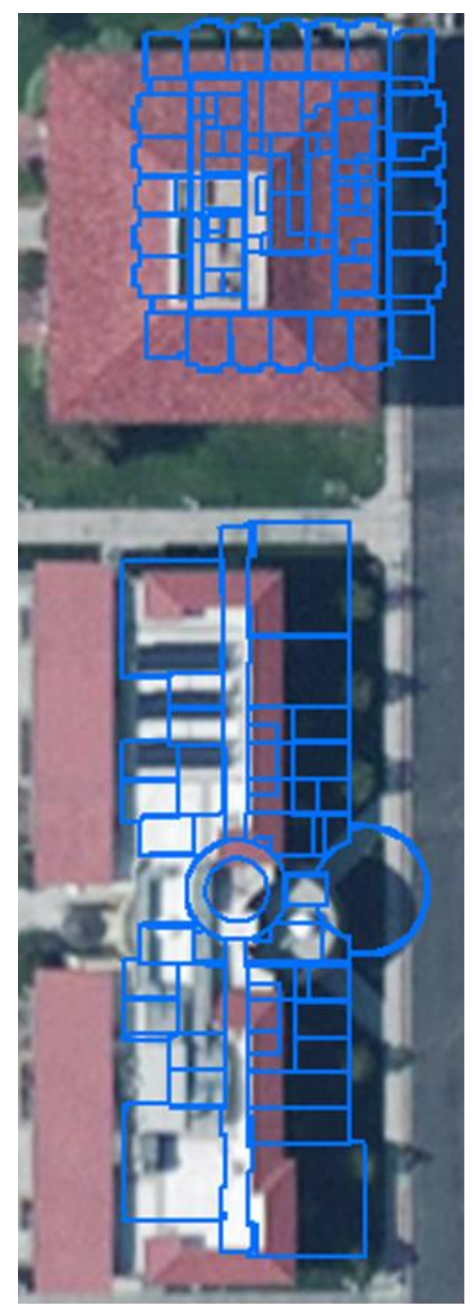

Original

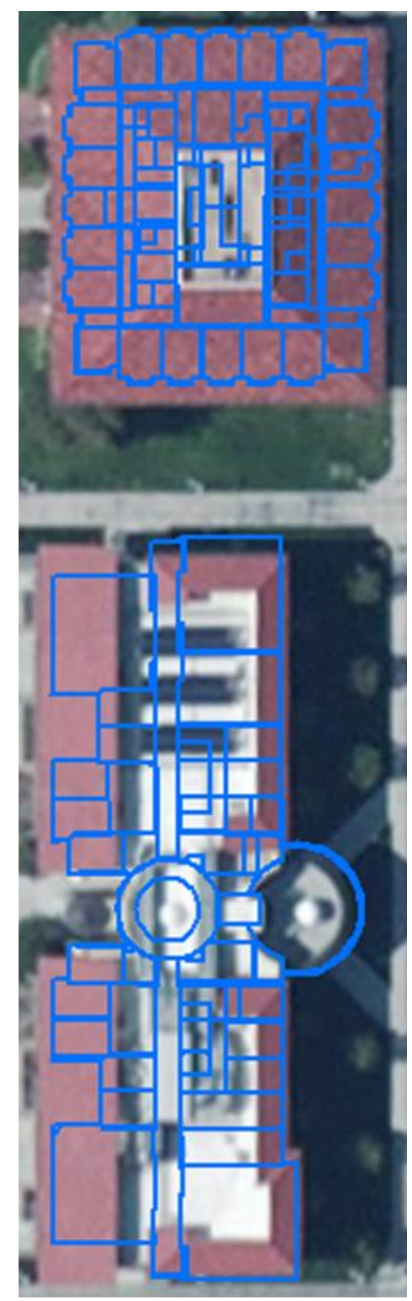

Shift Alignment

Figure 5-1: Drawing Alignment

\subsubsection{Drawings}

The shapefiles provided by the client did not have as much detail geometry as displayed in the PDF floor plan drawings (Figure 5-2). The floor plan documents provided a room number and information how the areas in the building were utilized. Other details in the floor plan included interior and exterior stairs, thickness of walls, room entry doors and building exit doors. Adding stairs to the data requires verification to original drawings to ensure the building code dimensions set for stair areas. However, in the geodatabase, interior and exterior stairs were included as coded values in the Corridor domain which identify all exit areas in a building. 


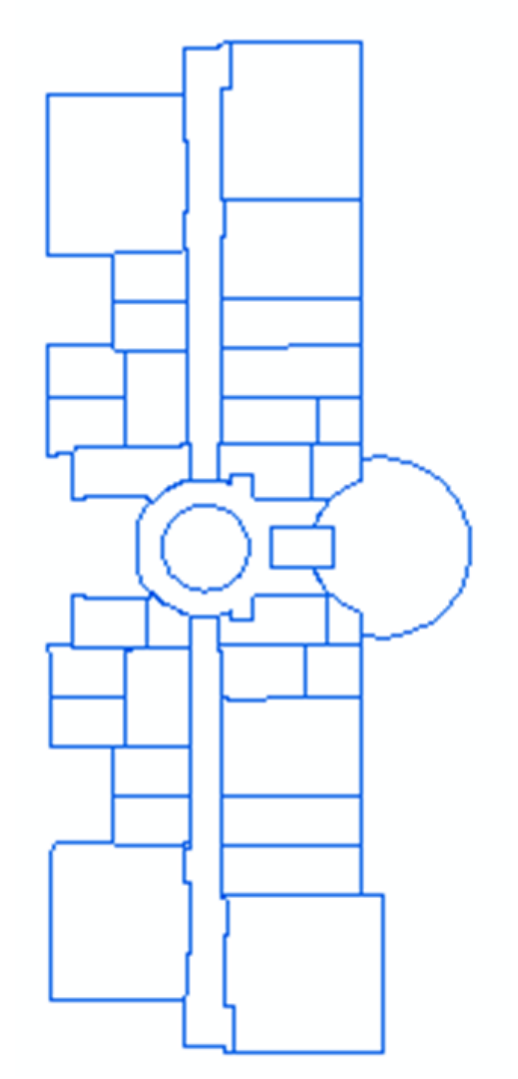

Shapefile

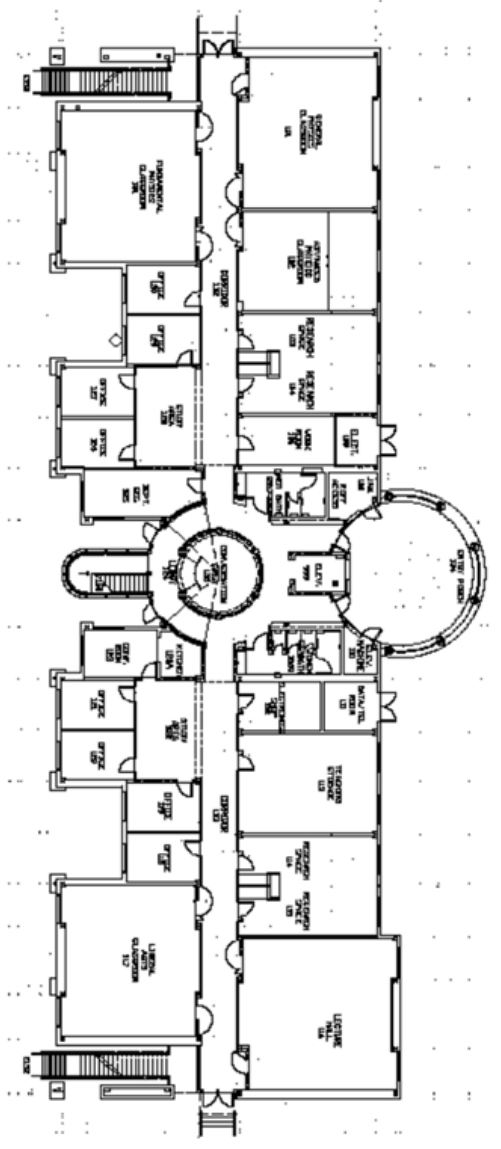

PDF Documentation

\section{Figure 5-2: Shapefiles and PDF Documentation}

The floor overlays displayed line variances along the main walls of the building (Figure 5-3). The blue line indicates floor level 1 and the red indicates floor level 2. Two reasons for the variances include differences in the floor plan and wall edges. These were not corrected in the data. It would require verification against the original source or the creation of new architectural drawings. However, this project is a proof of concept and therefore the data were a fair representation of the environment. If the project expands beyond this prototype, new datasets are highly recommended. Building codes require high level of accuracy for emergency planning and it is important to identify potential dangers surrounding those areas. For example, there are two mechanical rooms next to the bathrooms in Appleton Hall. In an emergency scenario such as a fire or an earthquake, it is important to identify the surrounding areas to ensure they are safe pathways. Electricity and water are dangerous and both are adjacent to main pathways leading to the exit of the building. This information is important in safety planning in assessing alternate building exits, and ensuring the appropriate safety equipment for those environments. 


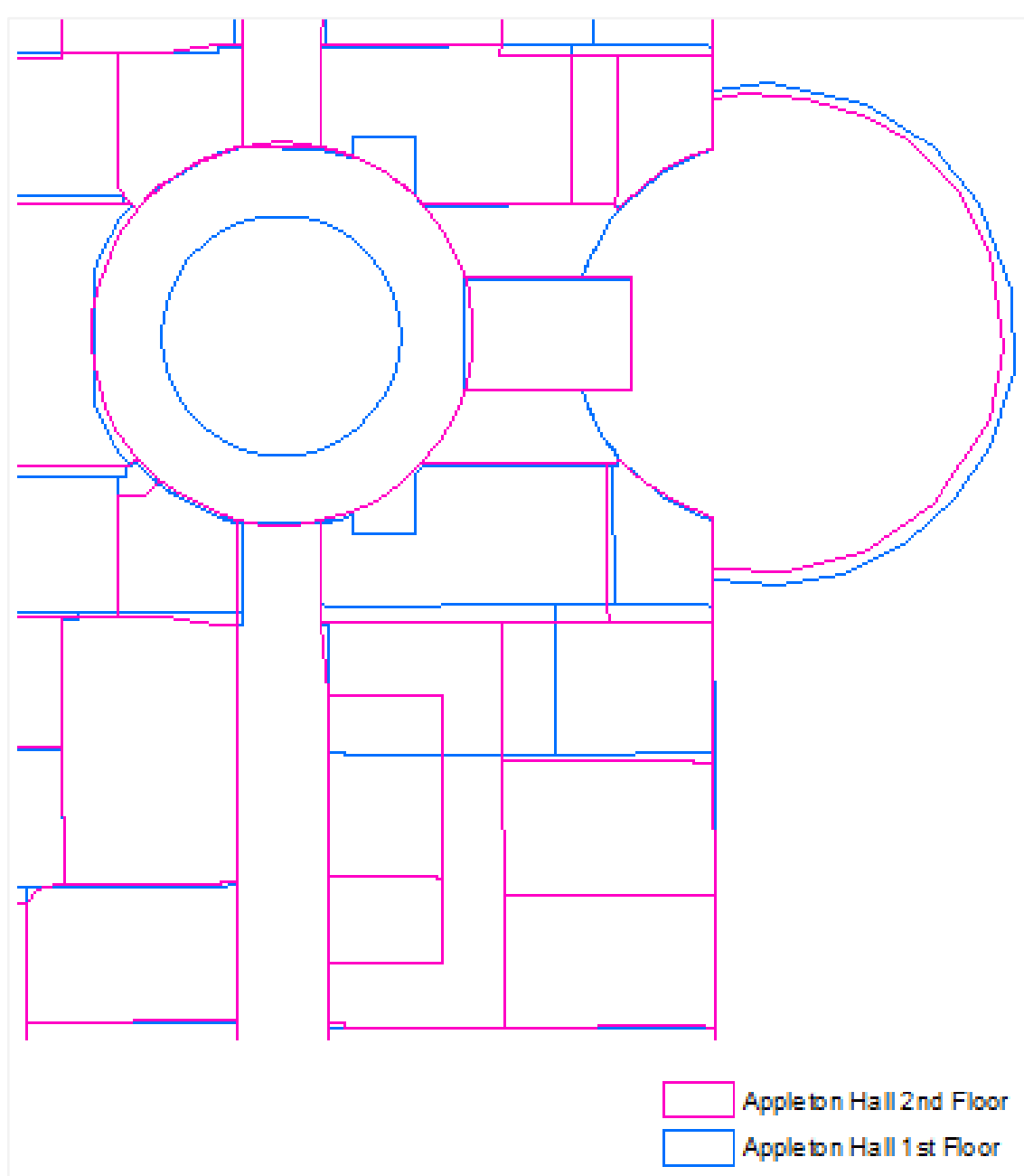

Figure 5-3: Floor Level Variances

\subsubsection{Safety Assets}

Fire extinguisher data did not have any attribute information in the dataset provided by the client. The room locations were never populated. Fire extinguishers were compiled from paper floor plans and room numbers were verified against an Excel spreadsheet. A feature class was later created and fire extinguishers were populated without attribute information. Fire extinguishers were extracted from the original dataset for the test areas to create a new feature class for the project. Other types of safety equipment were included to represent a more complete safety inspection process in the campus environment. These features included the fire alarm control panel, sub panel, pull station, and strobes. The features were collected by verifying equipment types visually through a walk-through of the two buildings ensuring their location on a paper floor plan. The points were added to the dataset in an ArcMap linking each of the features to an Inspection and Condition Domain in the geodatabase. 


\subsection{Data Creation}

Having a shapefile for each floor level as provided by the client made managing data a challenge for a campus with 60 buildings. Therefore, it was necessary to create new data for this project. The data required organizing and several processes of data scrubbing to create the geodatabase and feature classes needed for the project. The geodatabase contains two types of feature classes, a set for scrubbing, and the final feature classes for the project.

\subsubsection{Feature Classes}

The first step in creating new feature classes involved adding a floor level field for each of the building shapefiles and merging the shapefiles to create a new feature class. This process is covered in Section 4.4.1. The output was a single feature class containing all data, which served as a depository for extracting data into new feature classes. The name of the depository is DataMerge.

DataMerge was duplicated to create the first final feature class named Rooms in the geodatabase. Figure 4.2 in the previous chapter displays the attribute fields and domain associations for each of the final feature classes. The next scrubbing process included the DataMerge feature class by selecting floor level features through a definition query by floor level. The features were selected and exported as a new floor level feature class. The process was repeated for each of the four separate feature classes (Figure 5-4).
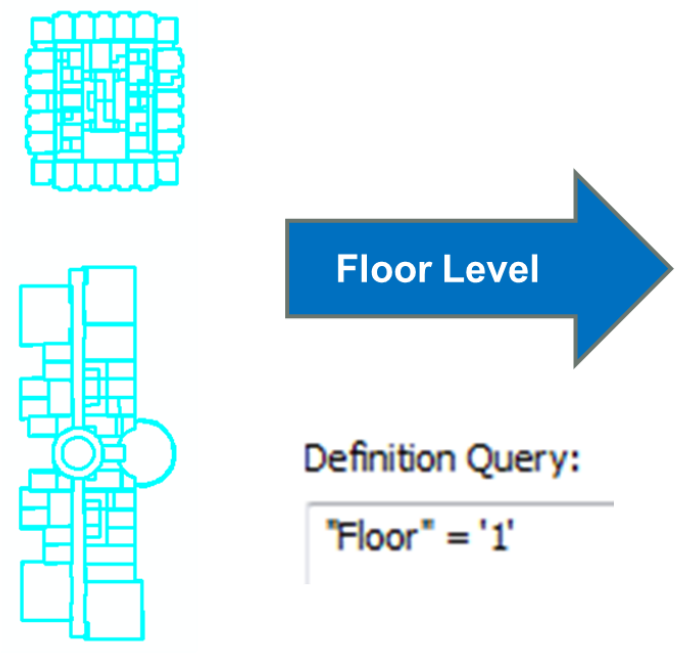

Definition Query:

"Floor" = '1'
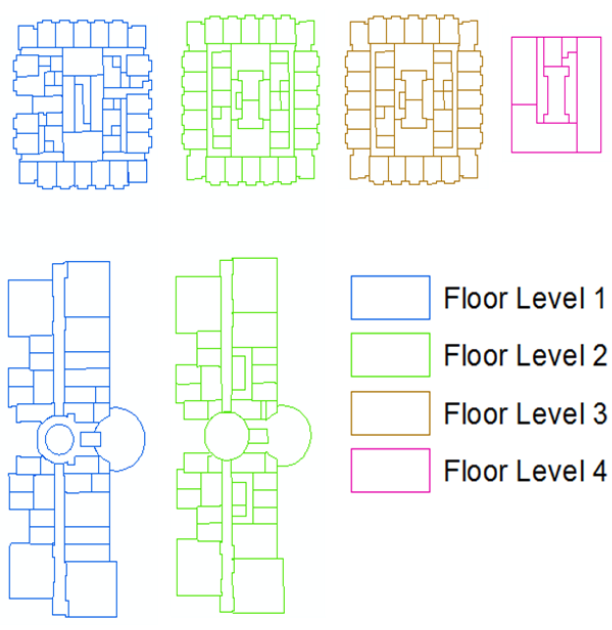

DataMerge

Figure 5-4: Creating Floor Level Feature Classes

The next phase merged the individual room polygons into a single floor outline. The process was repeated for each floor level (Figure 5-5). 


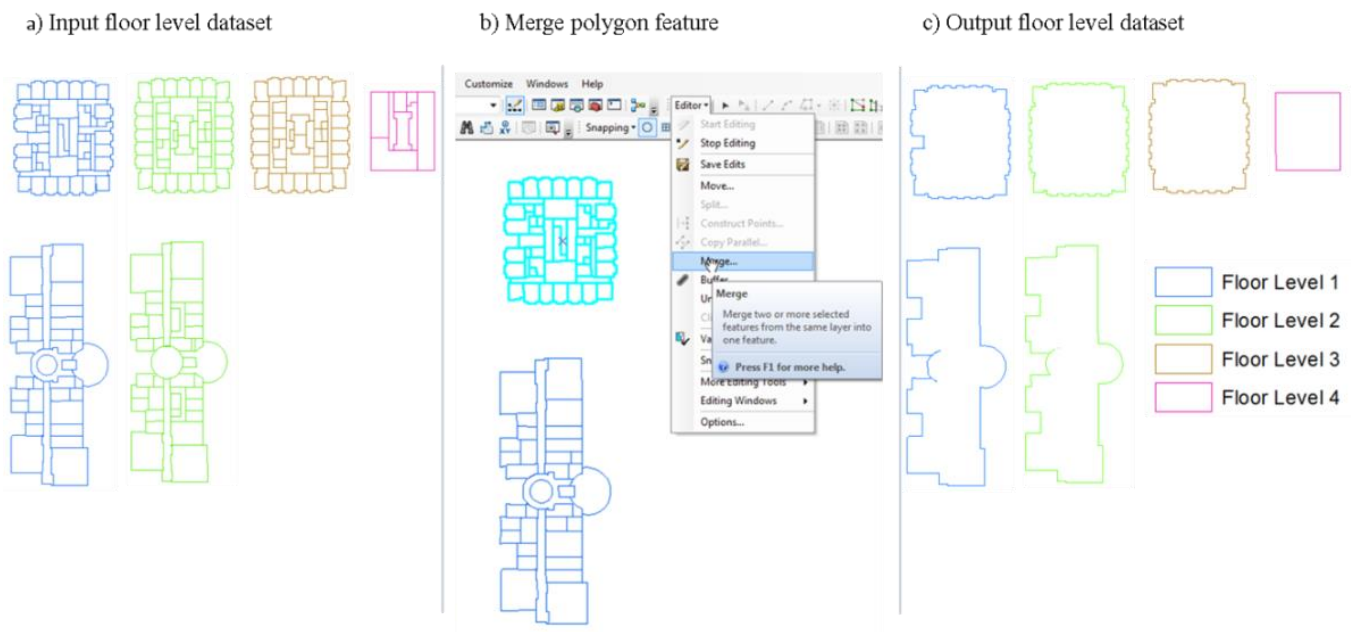

\section{Figure 5-5: Floor Outlines}

The floor outline for level 1 was duplicated to create the next feature class named Buildings which represent the building footprints for the test locations. A final geoprocessing merged all floor level feature classes to create the final Floors feature class for the project. The result were a single feature class with all floor levels (Figure 5-6).
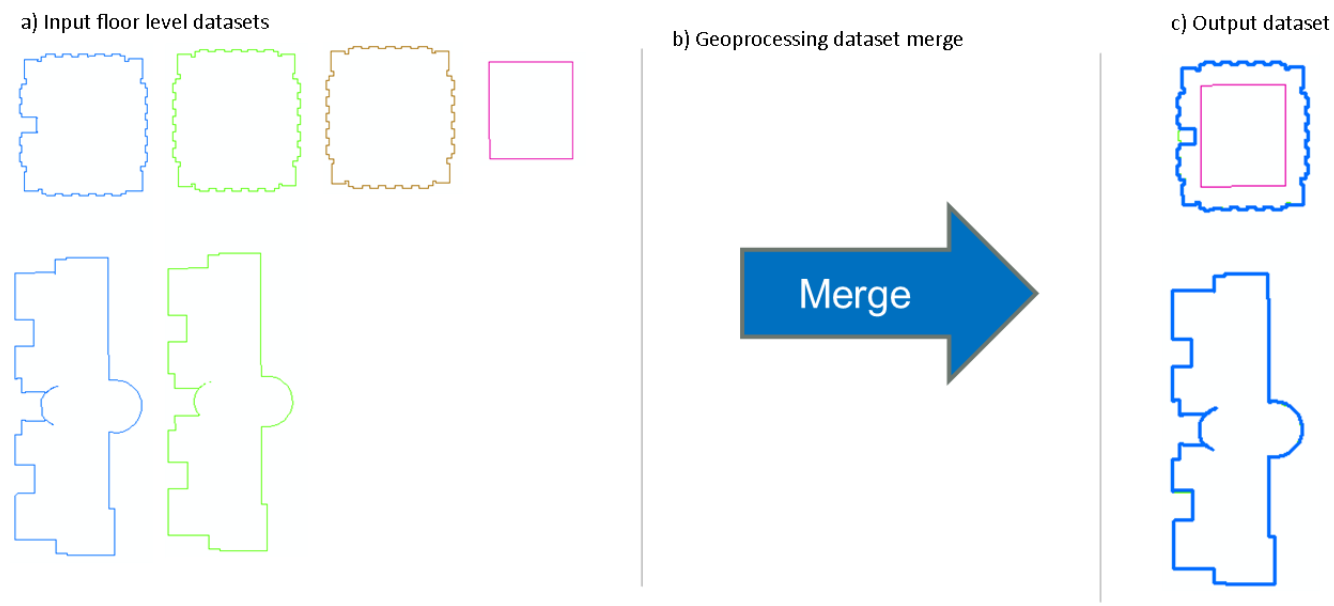

\section{Figure 5-6: Final Floors Dataset}

The client provided a dataset containing the location of campus fire extinguishers. In an ArcMap edit session, the features were selected and exported as SafetyAssets in the geodatabase. A new dataset was created which provided the location for each of the safety assets located in Appleton and East Hall. The final feature classes (Figure 5-7) used to develop the application included Buildings, Floors, Rooms, and SafetyAssets. 


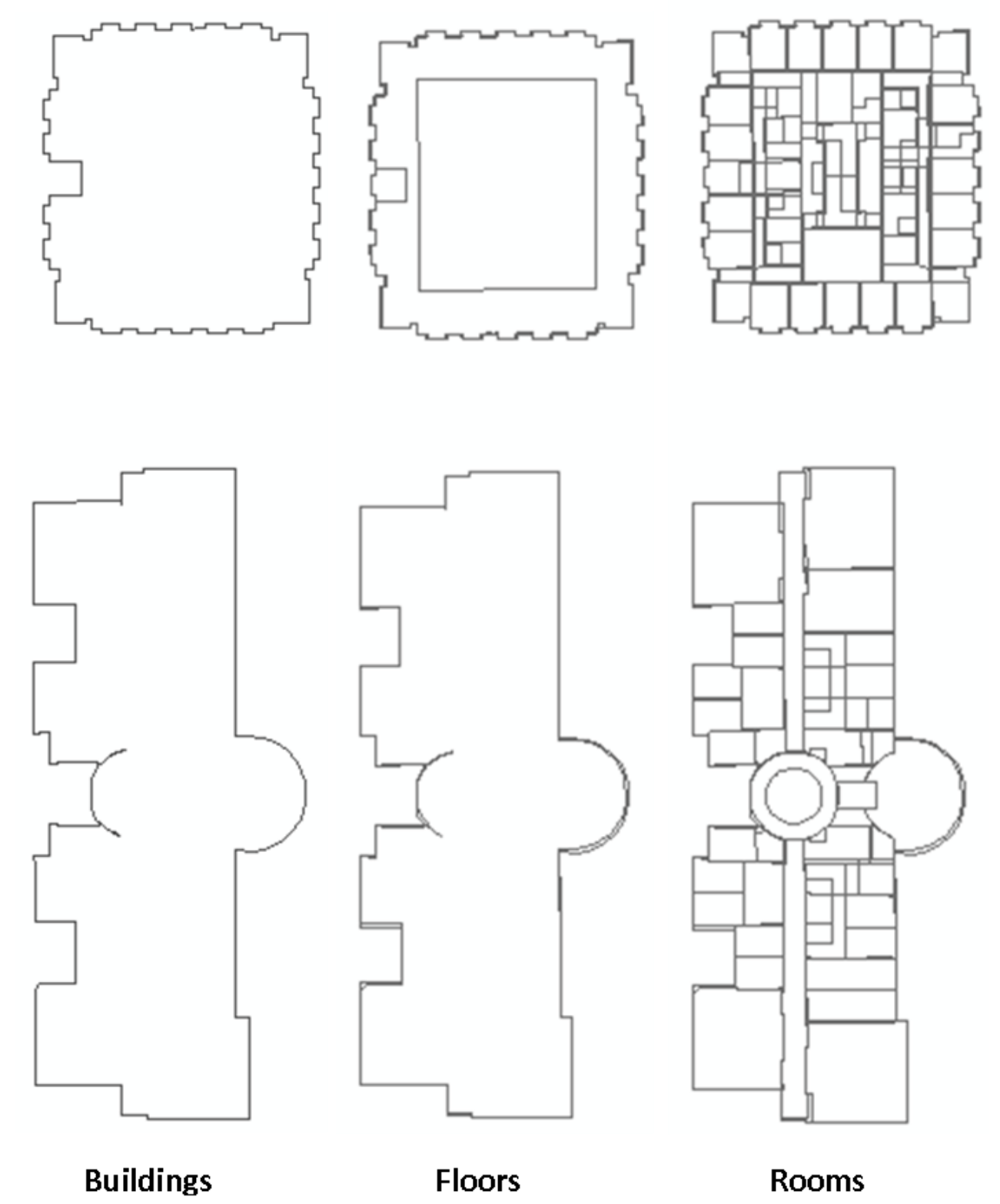

Figure 5-7: Final geodatabase feature classes; Buildings, Floors, and Rooms

\subsubsection{Organizing Subtypes and Domains}

Using a four-digit numeric code allows the rooms to be categorized and displayed by campus use and room types. Domains organized the data by a category classification and further defined classes by description type. Boolean domains, including Inspection and Condition, were also included in the design. The domains and subtypes were organized to address the primary spatial questions of the project: What type of room? What is the equipment by type and what is the inspection cycle? Knowledge of the room type and surrounding areas allows staff to confirm the appropriate safety equipment for the environment in a university campus. These factors determine the appropriate safety equipment, inspection cycles, and efficient safety planning. For example, Figure 5-8 
illustrates the Rooms feature class subtypes and domain links to the default subtype (Classroom coded value 1100). The assigned domain includes three types of classroom descriptions. The Room feature class links the RmDescription field to the Classroom geodatabase domain.

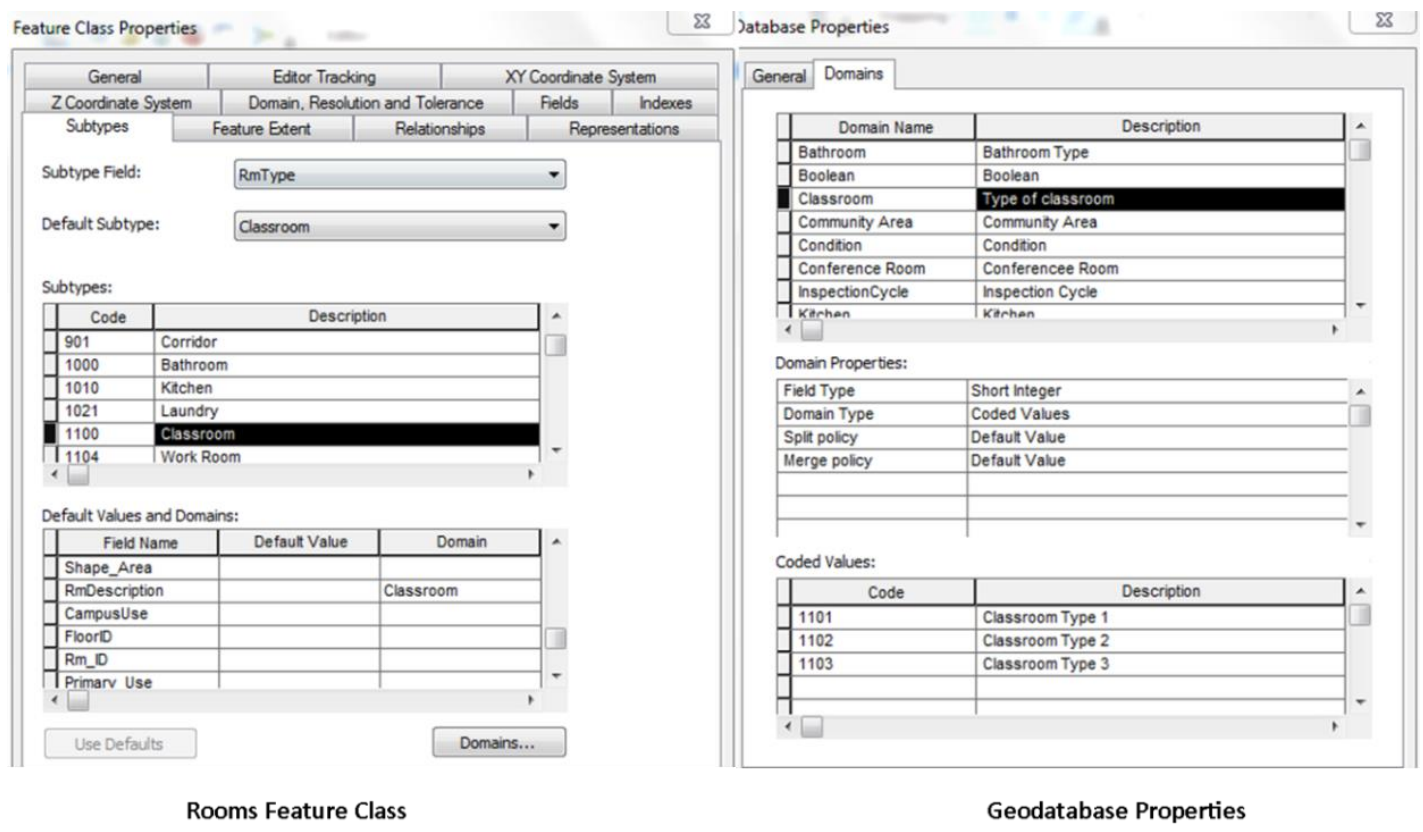

Figure 5-8: Subtype and Coded Value Domain

Safety assets were assigned a 1500 range coded value. Two Boolean domains were created to identify the condition of the equipment and inspection cycle. Feature subtypes for each of the safety assets were linked to an Inspection and Condition domain. Inspection cycles vary depending on equipment and location area. For instance, fire extinguishers require an inspection cycle of 30 days. The inspection domain was coded with values to represent different inspection cycles needed for equipment. The condition domain included values to report the condition of equipment when inspected. Figure 5-9 illustrates a fire extinguisher and the links to domain associations. The process was repeated for all safety features in the SafetyAssets feature class. 

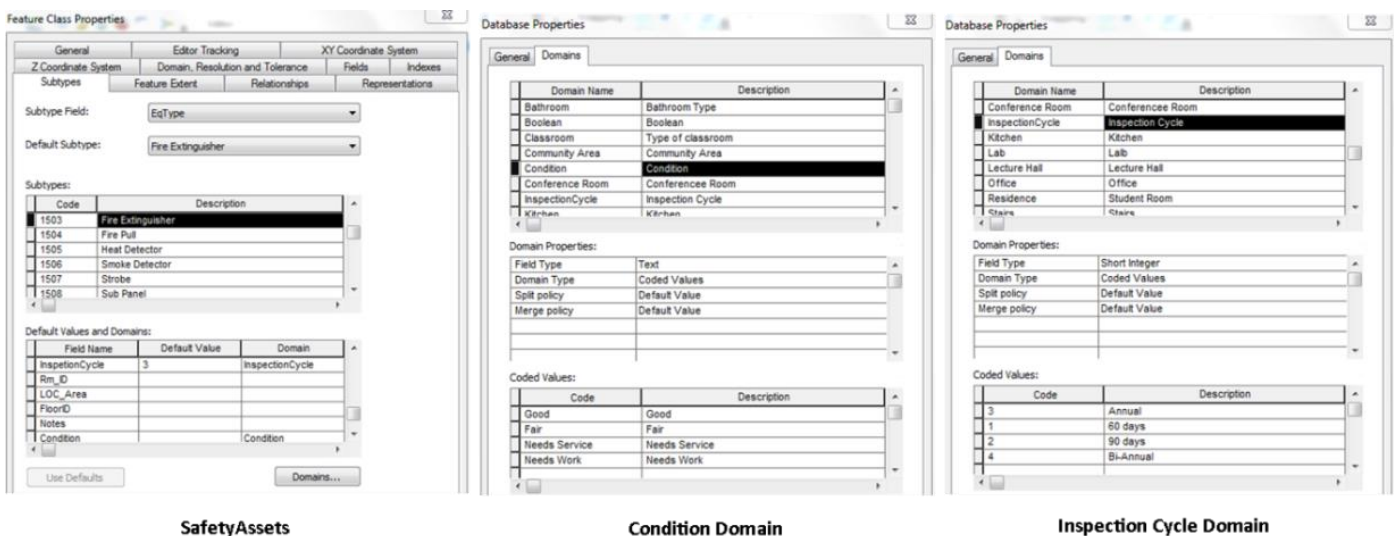

Inspection Cycle Domain

Figure 5-9: Safety Assets Domains

\subsection{Web Implementation}

Web feature services allow access to geographical data through the Web. Four feature services were published to an ArcGIS Online organization account and prepared for Web development. These were organized by floor levels except for Building. The map services were published in this manner for two reasons. First it facilitates an inspection process without having to filter information. The user can click on a map layer and view the data according to floor levels. Second, it enables file attachment and uploads for the selected feature. Figure 5-10 illustrates Building and Floor Level, and Figure 5-11 illustrates Room Layer and Safety Assets. The publishing process to develop the Web application followed a service menu wizard in ArcMap to connect host servers for Web publication. 


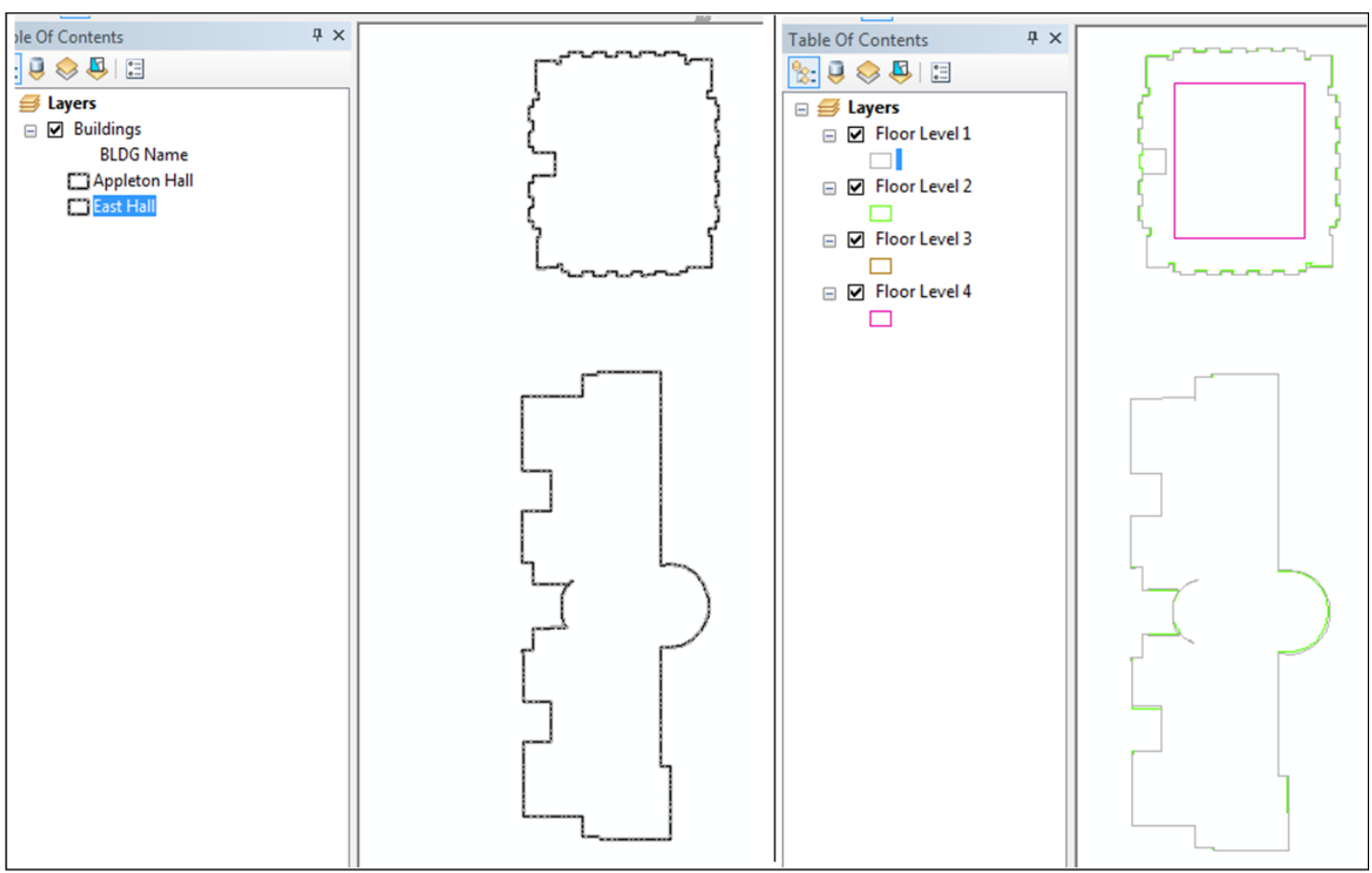

Building Feature Service

Floor Feature Service

Figure 5-10: Building and Floor Level Feature Service 


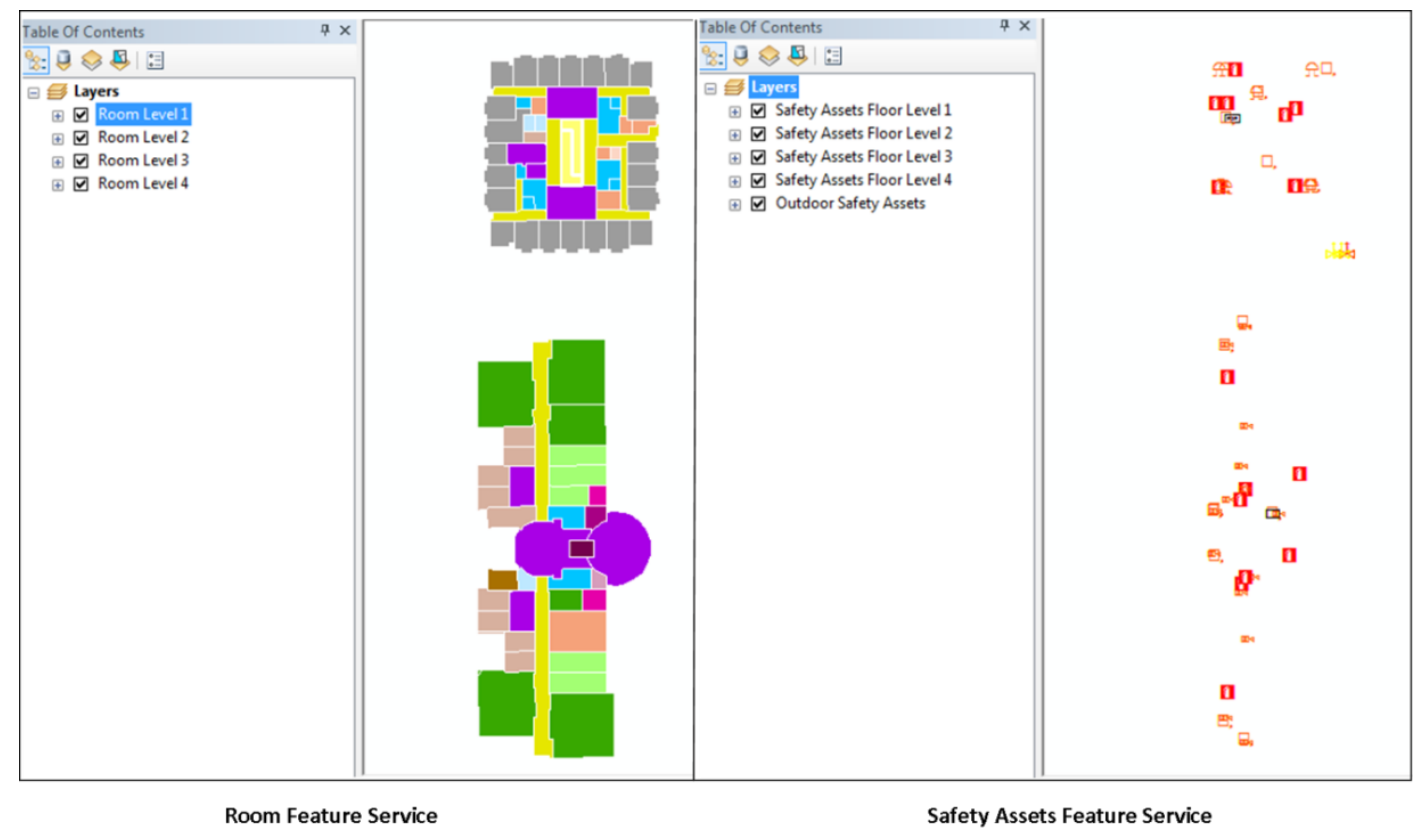

Figure 5-11: Room and Safety Assets map layers

\subsubsection{Web Publishing}

The content page included the feature services available for Web development. The feature layers included map layers for the service (Figure 5-12). The service definition included data associated with the Web services such as tables, queries, and editing fields. Each feature services included parameters and capabilities. Map layers were enabled for file attachment uploads, and parameters were set for feature access, with operation privileges for users to update feature attributes only (Figure 5-13). Selecting the feature layer properties protected the integrity of the data by granting permissions to those with data access. It also facilitated the inspection process to update selected features and upload file attachments to the correct feature. The Item Description window included a summary, tags, description, credits, and access use.

\begin{tabular}{|c|c|c|c|c|c|}
\hline Folders & + Add & Iten & m Create Map & \& Share & X Delete 4 Move * \\
\hline \multirow{2}{*}{ NEW ${ }^{-x}$ DELETE } & $\square$ & & A Title & & Type \\
\hline & $\square$ & 望 & Building_Layer & $=$ & Service Definition \\
\hline maricruz_escarcega_msgi & $\square$ & 0 & Building_Layer & $=$ & Feature Layer \\
\hline Show & $\square$ & 0 & Floor_Level_Features & $=$ & Feature Layer \\
\hline All & $\square$ & 圆 & Floor_Level_Features & $=$ & Service Definition \\
\hline $\begin{array}{l}\text { Maps } \\
\text { Layers }\end{array}$ & $\square$ & 圆 & Rooms & $=$ & Service Definition \\
\hline Apps & $\square$ & (0) & Rooms & $=$ & Feature Layer \\
\hline \multirow[t]{3}{*}{$\begin{array}{l}\text { Tools } \\
\text { Files }\end{array}$} & $\square$ & 俤 & SafetyAssets_floor_level & $=$ & Service Definition \\
\hline & $\square \quad$ & (0) & SafetyAssets_floor_level & $=$ & Feature Layer \\
\hline & $1-8$ of 8 & 8 rest & sults & & \\
\hline
\end{tabular}

Figure 5-12: Service Layers 


\section{Layers}

\begin{tabular}{|c|c|c|}
\hline Safety Assets Floor Level 2 & $\leftrightarrow$ & Export to Shapefile \\
\hline & +9 & Export to CSV file \\
\hline Salecy Assets rioor Lever 3 & स्व & Export to FGDB \\
\hline Safety Assets Floor Level 4 & 열 & Service URL \\
\hline Outdoor Safety Assets $\mathbf{\nabla}$ & $\begin{array}{l}0 \\
0.9 \\
9\end{array}$ & $\begin{array}{l}\text { Disable Attachments } \\
\text { Time Settings }\end{array}$ \\
\hline
\end{tabular}

Enable File Attachments

\section{Properties}

\begin{tabular}{|c|c|c|c|c|}
\hline \multicolumn{2}{|l|}{ Tags } & \multicolumn{3}{|c|}{ Safety assets floor level $\times$ Add $\operatorname{tag}(s)$} \\
\hline \multicolumn{2}{|l|}{ Credits } & \multicolumn{3}{|l|}{ M. Escarcega } \\
\hline \multicolumn{2}{|c|}{ Delete Protection } & \multicolumn{3}{|c|}{$\checkmark$ Prevent this item from being accidentally deleted. } \\
\hline \multirow[t]{2}{*}{ Extent } & & Left: -117.16 & Right: $\quad-117.16$ & \multirow{2}{*}{ SET EXTENT } \\
\hline & & Top: $\quad 34.06$ & Bottom: 34.06 & \\
\hline Editing & \multicolumn{4}{|c|}{$\begin{array}{l}\text { Enable editing and allow editors to: } \\
\text { Add, update, and delete features } \\
\text { Update feature attributes only } \\
\text { Add features only }\end{array}$} \\
\hline Export Data & \multicolumn{4}{|c|}{$\checkmark$ Allow others to export to different formats. } \\
\hline Sync & \multicolumn{4}{|c|}{ ( Enable Sync (disconnected editing with synchronization). } \\
\hline Track Edits & \multicolumn{4}{|c|}{$\begin{array}{l}\text { Keep track of who created and last updated features. } \\
\square \text { Editors can only update and delete the features they add. }\end{array}$} \\
\hline
\end{tabular}

Layer Properties

\section{Figure 5-13: Enabling Feature Layer Properties}

\subsubsection{Creating a Web Map}

The ribbon in the My Content window from ArcGIS Online, displayed an icon for creating new web maps (Figure 5-14). Feature layers were added and configured to display selected attributes fields when creating pop-up menus and uploading attachments (Figure 5-15). Each layer required configuration to the pop-up. When the maps were published as a feature services, all of the attributes were inherited. However not all of them were needed in the pop-up menu. Only the attributes for the inspection process were included for viewing and the selected attributes allowed for a drop down menu in the application. The subtypes and domains created in the geodatabase enabled the Web map to execute a pull down menu for selected attribute fields. The maps were styled and selected for a Web application. 


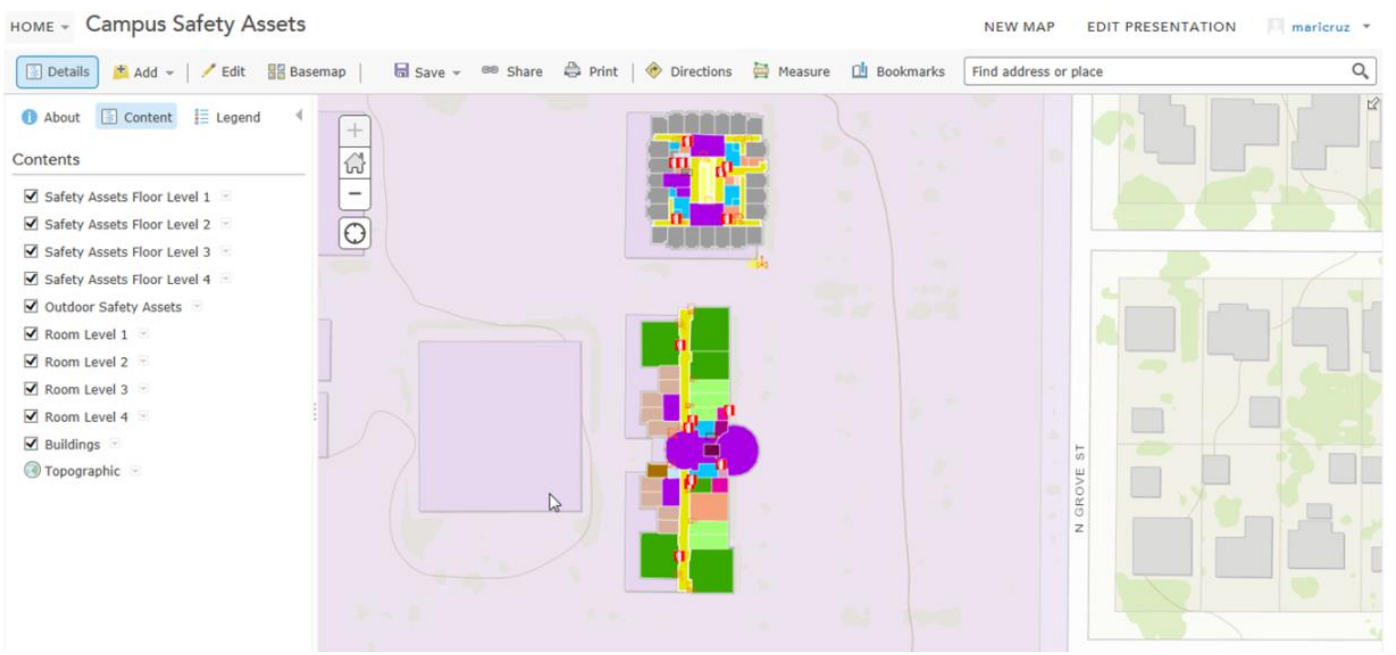

Figure 5-14: Creating a Web Map

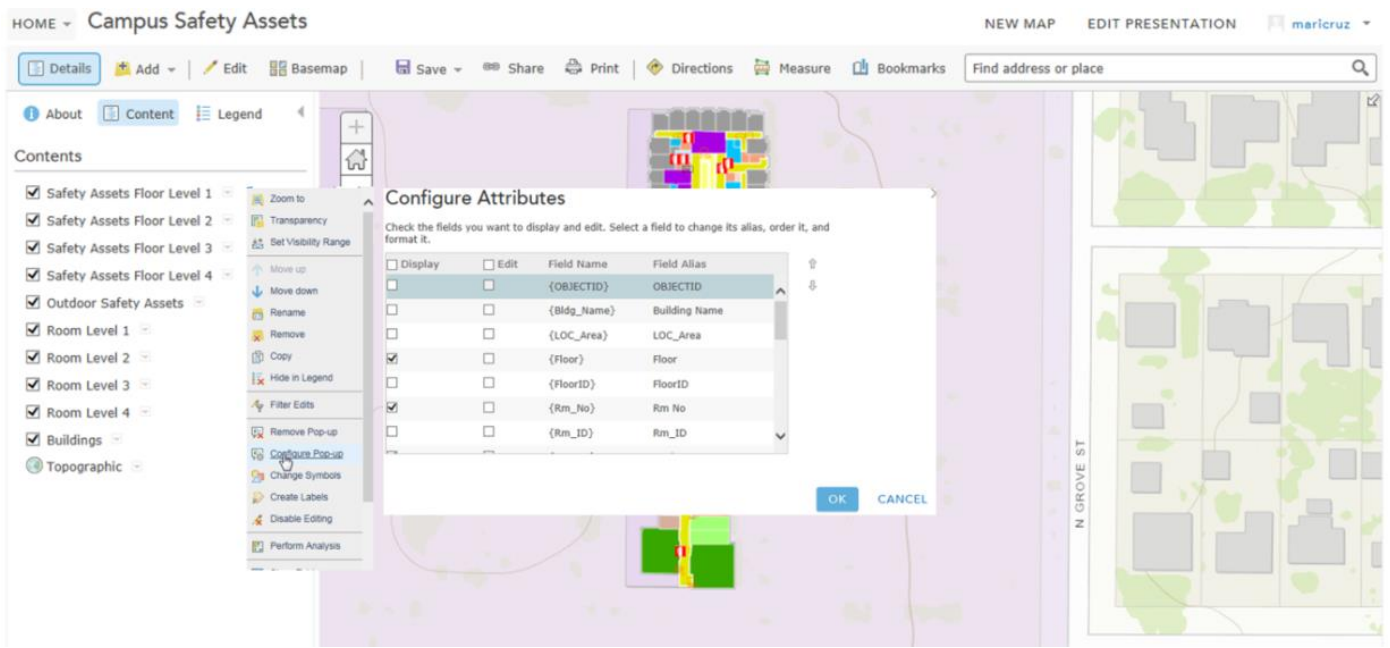

\section{Figure 5-15: Pop-up Configuration}

\subsubsection{Web Application}

The Web maps were published and shared using a pre-configured Web application template available through the ArcGIS Online organization account. Templates are preconfigured with widgets and base map layers that require arrangement by selecting the desired widgets for the Web application. For this project, the Web application widgets included zoom capabilities, map layers, basemap gallery, map legend, user enabling editing, measure tool, map detail description, and print capabilities. The zoom capability allows the user to zoom at different scale levels. The map layers widget allowed for the selection of the inspection by room level, safety asset level, and building name when performing inspections. Map layers are available for safety crews facilitating the inspection process. A pop-up menu describes the feature and allows safety crews to make edits to selected attributes enabled with a designated drop down menu. 


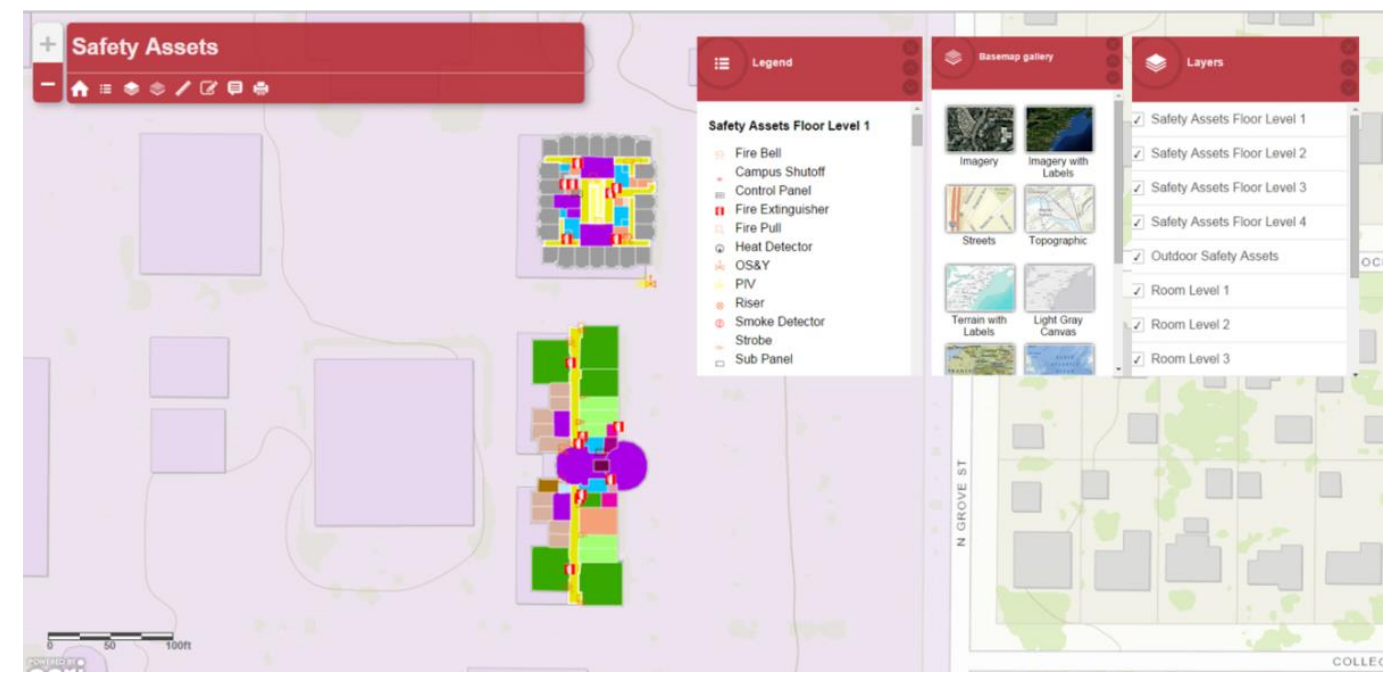

Figure 5-16: Web Application

\subsection{Summary}

This chapter focused on the implementation of the project. It covered the visual variances in the drawings and how they were resolved. It also included the creation of datasets and the geoprocessing methods used to create the final feature classes for the project. It explained how the domains and subtypes were linked and organized in the geodatabase. The process followed with the creation of maps layers to publish as feature services to an ArcGIS Organization account for Web development. 



\section{Chapter 6 - Results and Analysis}

The goal and objective for this project was to provide a proof of concept for managing safety assets using GIS. This chapter explains the results and analysis of the project.

\subsection{Campus Buildings}

The project was limited to two buildings on the east side of the campus. One building has four floors while the other one has two floors. Implementing this solution campus wide would require an attribute field specifying the number of floors in the Buildings feature class. Having this information provides a visual perspective of the number of single story buildings and multilevel buildings (Figure 6-1). It also improves safety planning by identifying areas where emergency exits are limited by floor levels in a building. In a single story building, windows may serve as emergency exists, if needed.

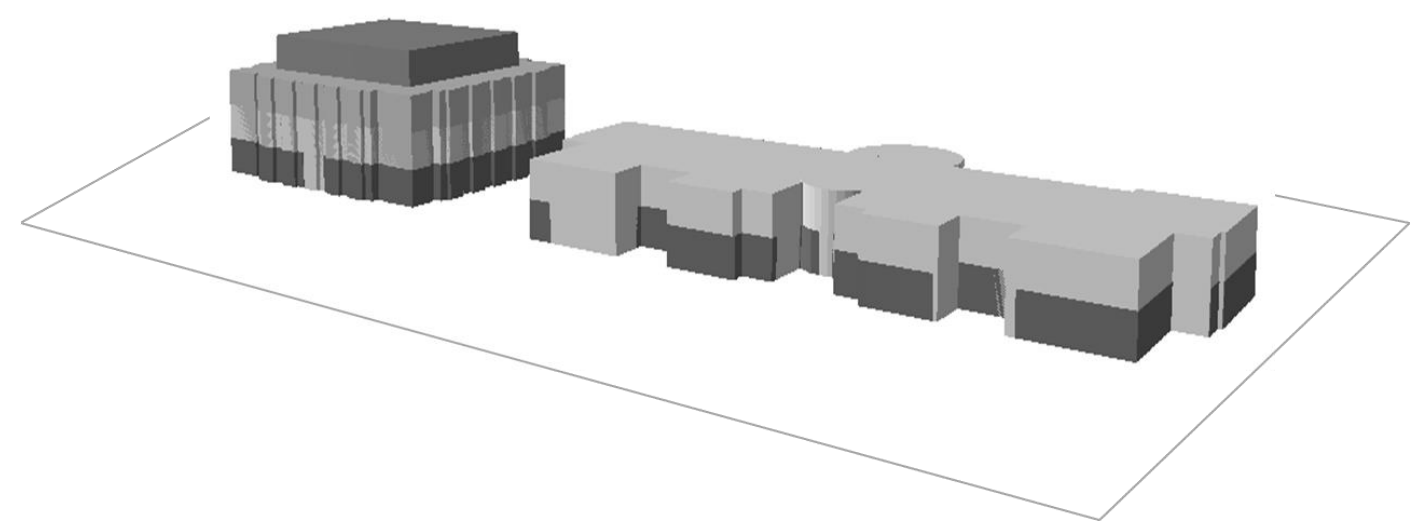

Figure 6-1: 3D Visual Perspective

\subsubsection{Walls}

The location of the main walls were inconsistent for all floor levels. Georeferencing data using aerial imagery is not recommended for generating building footprints for safety planning. Aerial imagery displays the rooftop of buildings and may not produce an accurate representation of building measurements. Without the architectural drawings, it is difficult to determine where the walls of the building are located using a rooftop as a building footprint. In addition, the scale and zoom capabilities may limit the accuracy of the image, and base map aerial imagery varies across software packages and in proprietary aerial images.

Dimensions for height and width provide accuracy to the interior and exterior proportions of a building, floor, or room. The ArcGIS software calculates the dimensions of the polygon features. Without structural engineering drawings, the accuracy of the geometry remains in question. Dimensions also assist in determining the capacity and use of a room area. Depending on the construction, materials, insulation, and building purposes, the wall thickness in a building vary in size. Outside of a test environment, having accurate measurements or reference architectural drawings is highly 
recommended. Figure 6-2 illustrates the inconsistency in the wall edges in Room layers for East Hall.

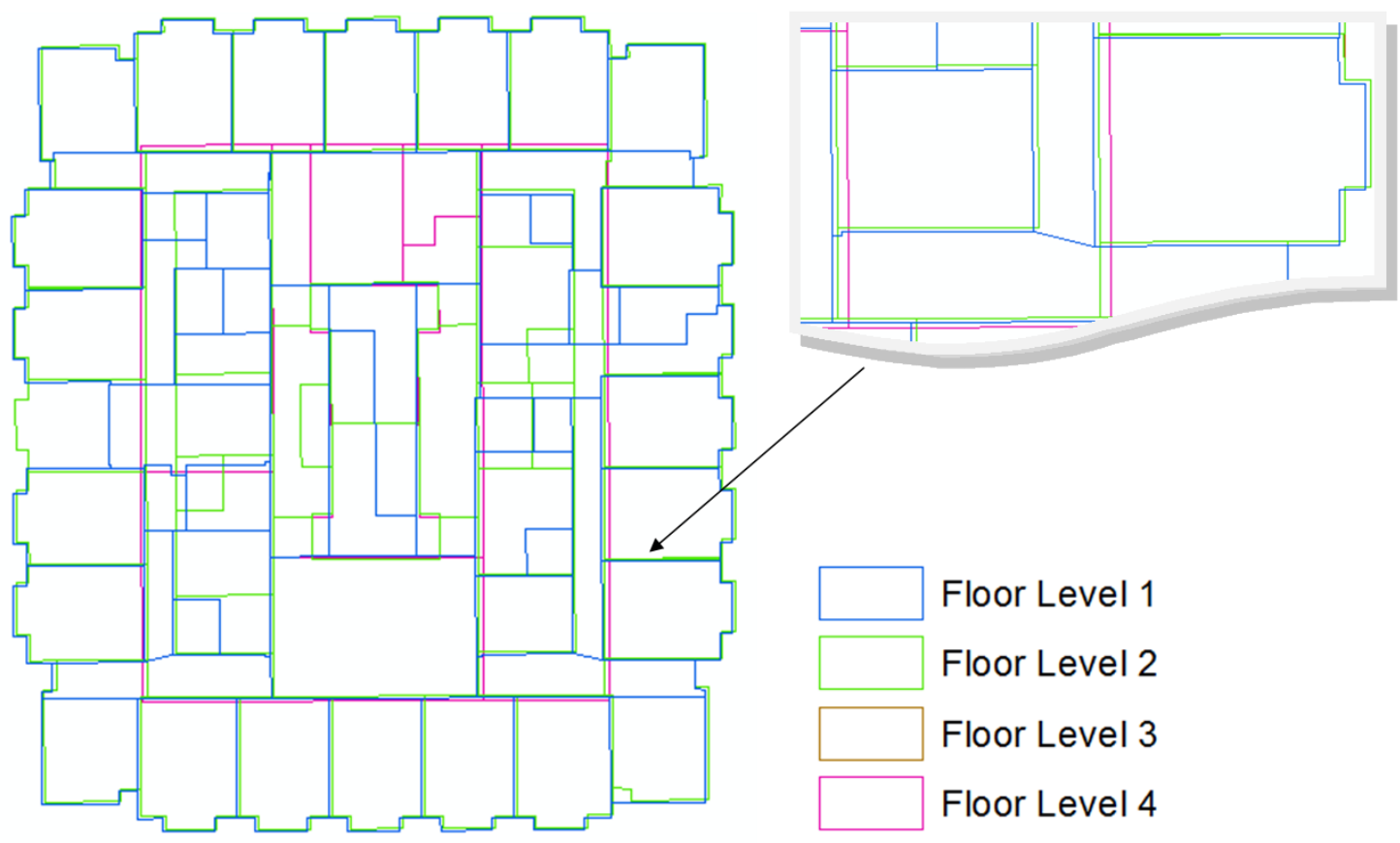

Figure 6-2 : Wall Variances

The geometry was most visible around the dome areas of Appleton Hall. The dome areas for floor level 1 were overlapping with data drawing for floor level 2 (Figure 6-3).
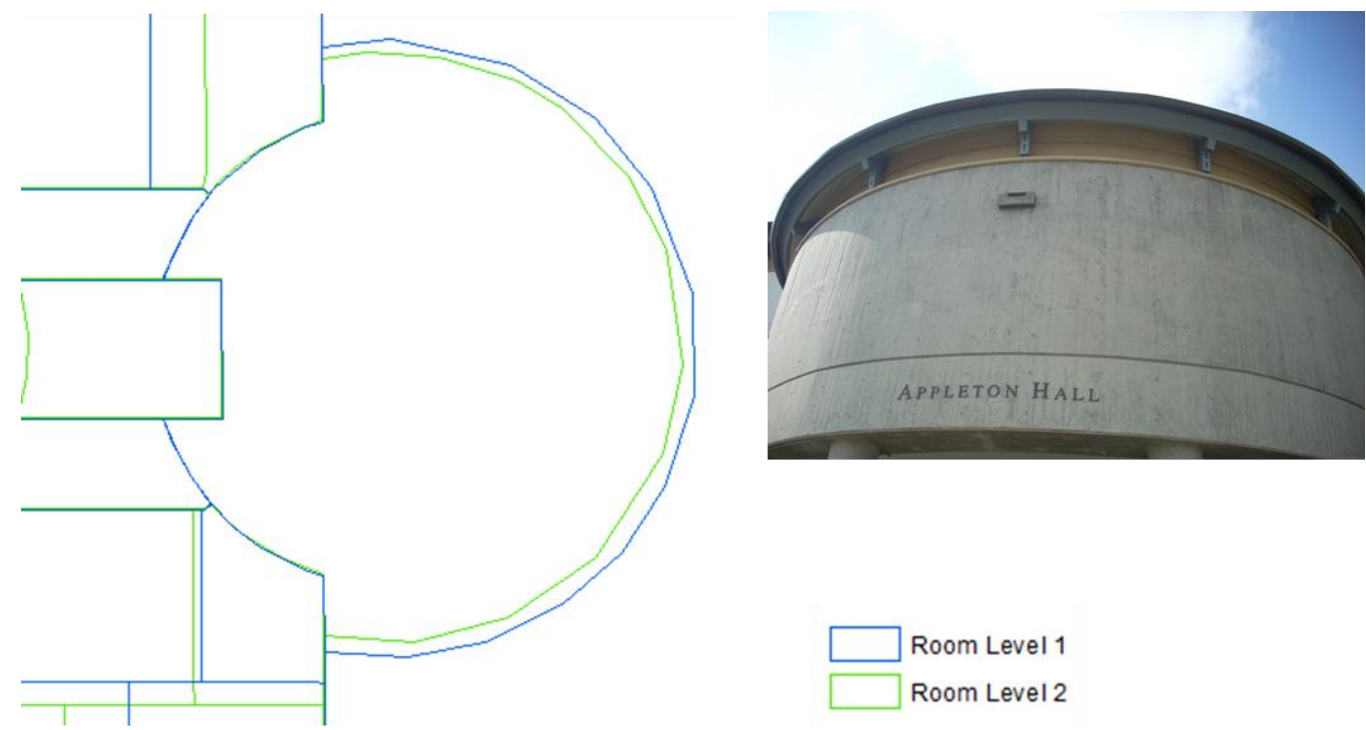

Figure 6-3: Appleton Hall Dome 


\subsubsection{Merging Data}

Merging the data required adding a floor level attribute to each of the shapefiles. This was necessary for the scrubbing process, organizing data, and converting the shapefiles into feature classes. When the data were merged, the geoprocessing tool created a new Object ID field for the output feature class. However, the prior Object ID field remained in the attribute table. To avoid confusion it was deleted from the data.

\subsubsection{Corridors}

Community areas in the data were identified as locations where people gather for social events. These areas in the original data were labeled as a room feature. Treating areas this way had the effect of eliminating the corridors from the area. The solution was to classify the features correctly. In some instances, a corridor may lead to a building exit and it is important to identify those areas when developing data for safety planning. Figure 6-3 illustrates a community area where the corridor is not included. This area has four building exits.

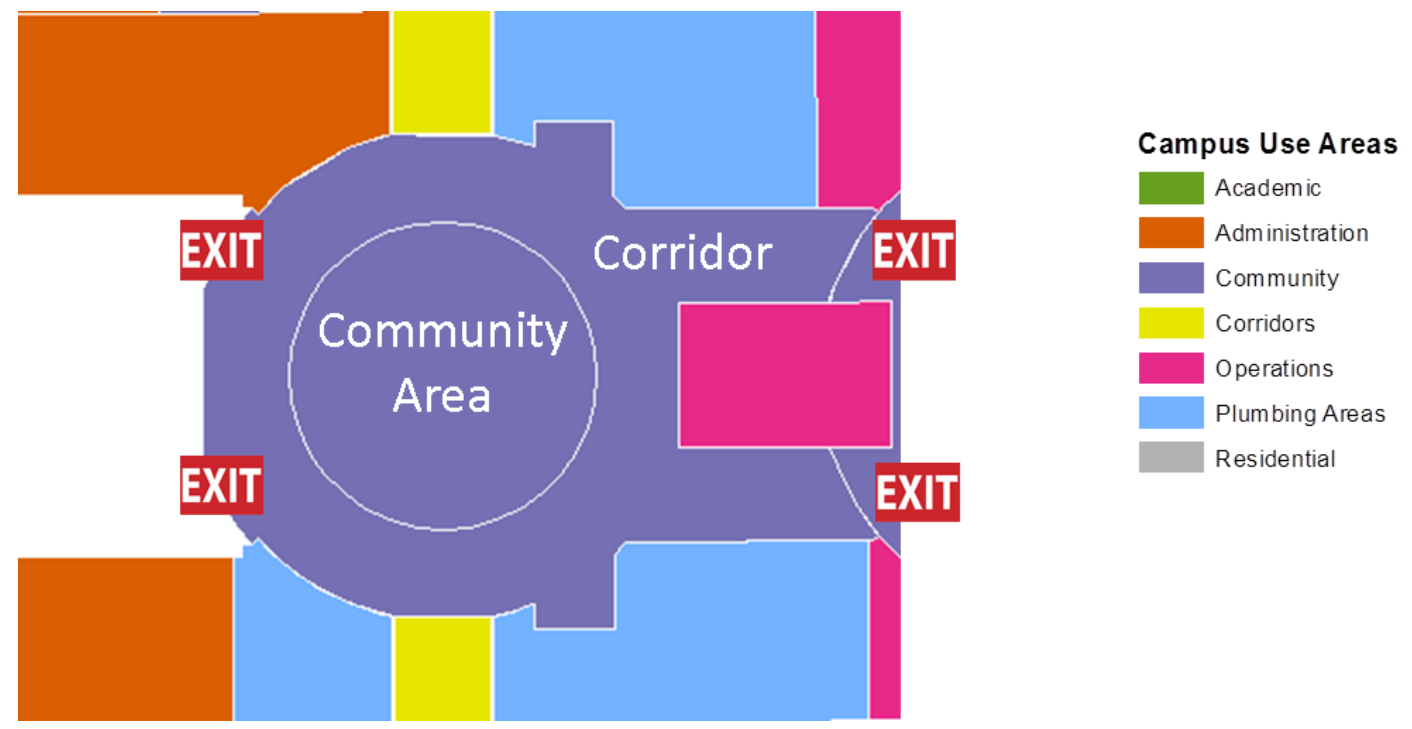

Figure 6-4: Corridors

\subsection{Fire Devices}

Collecting safety equipment data did not go as expected. Not all safety assets were collected as initially planned and not all areas were accessible for walk through. The fire control panel for Appleton Hall was located in a closed room. However, in East Hall, the fire alarm panel was located in a visible area. Data for fire strobes, heat detectors, and smoke detectors were not provided by the client and required visible inspection to the device.

The preliminary proposal was to include smoke detectors and heat detectors as safety assets in the data. These devices require regular inspections, battery testing, and replacement when damaged. The number of fire strobes, smoke detectors, and heat 
detectors inside a building required visual inspections and not all areas were accessible for visual inspections. This required additional planning and strategizing for the implementation of the project. These devices are often included in the fire architectural plans when buildings are constructed. Fire plans were not provided in the datasets. These devices are also attached to the walls and ceilings of the interior and exterior of buildings.

Fire safety equipment collection was resolved by visual inspections and floor walk through to the common corridors in the buildings. This included exit areas, hallways, and stairs. The data were referenced using the floor plan layout and the points were added to the feature class in an ArcMap edit session.

\subsection{Summary}

This chapter described scenarios during the implementation process. These included wall geometry variances and data collection alternatives. Without original drawings, the inconsistencies with the geometry remain unresolved. Implementing a project for safety planning in a campus environment requires accurate dimensions and architectural drawings for all datasets. This includes all of the architectural plans for the building. 


\section{Chapter 7 - Conclusions and Future Work}

The purpose of this project was to develop a solution for managing the inspection process for safety assets on a university campus. There were three objectives for this project: classify buildings on campus equipped with sprinkler systems; find where safety equipment is located inside a building including floor level, room number, and room type; and identify the type of safety equipment, condition, inspection cycle, inspection date, and person doing inspection. The objectives were achieved by creating and organizing a geodatabase with coded values and domain associations. This chapter summarizes the project deliverables and data useful for additional work.

\subsection{Summary of Project Deliverables}

The geodatabase contains two types of Feature Classes: those used for scrubbing, and final Feature Classes used for creating the project's final solution. Both serve as references for any future work.

Feature Classes used for scrubbing data included AllFloorLevels, DataMerge, FloorLevel1, FloorLevel2, FloorLevel3, and FloorLevel4. Feature Classes used to create the final solution included Buildings, Floors, Rooms, and SafetyAssets. Domains and subtypes are included in the final solution Feature Classes only.

MXD files contained map layers for each of the datasets. The MXD files were used to publish feature services to an ArcGIS Online organization account. MXD files included. Building_Layer, FloorLevel, Room, and Safety_Assets_floor. Layer files store the symbology, labels, scale, and properties of the layer. Layer files included RoomSymb, SafetySymb, and CampusUseSymb. Feature services included Bldg_layer, Floor_Level_Features, Room, Safety_Assets_floor_level. Each service includes a service definition. Web maps included Campus Safety Assets. The Web application included Campus Safety Assets. These were prototype settings to view and test the functionality of the solution in a Web environment.

\subsection{Future Work}

The existing data are ready for Web development or 3D modeling analysis for anyone interested in expanding the project. The data requires additional refining to attribute tables. For example, adding height and width dimensions to each of the dataset attributes to create 3D modeling. Knowledge of room capacity information is another attribute to consider for the Room feature class. Additional attributes to SafetyAssets may include First Aid Kits and CPR stations. Other data could include emergency doors and their locations for visualizing exit locations improve planning for evacuation areas.

Future considerations may include a configuration of ArcGIS Online Executive Dashboard. It is a customized Web application to view metrics and identify trends within a campus environment. The design requires additional planning to determine what information the client requires. Applicable examples for this data include ability to run reports when safety inspections are due by showing inspection cycles for the next 30 days and where equipment is located. Technical requirements for this kind of application 
include ArcGIS 10.1 for Desktop, ArcGIS Spatial Analyst extension, ArcGIS 10.1 for Server Standard or Advanced, Microsoft Internet Information Services (IIS), enterprise or workgroup geodatabase, and Microsoft ASP.NET Framework 4.0.

Data for this project included Z values for future work in 3D. Esri City Engine is a 3D design application. It has capabilities to integrate with most computer-aided drafting file extensions and GIS providing a visual perspective of building infrastructure in 3D. Datasets for future project work could include plumbing, electrical, or telecom. These types of datasets are useful geometric network analysis. Their geometry is a line feature. The existing geodatabase includes points and polygons feature. In a 3D model, an electrical, plumbing, or telecom dataset would display the complete fire alarm system architecture. 


\section{Works Cited}

Dangermond, J. (2003). Forward. In R. Tomlinson, Thinking About GIS. Redlands: ESRI Press.

Dangermond, J. (2014). ESRI User Conference. San Diego.

Esri. (2013, Fall). esri. Retrieved Augtust 23, 2014, from esri.com: http://www.esri.com/esri-news/arcnews/fall13articles/implementing-web-gis

Fu, P., \& Sun, J. (2011). Web GIS Principles and Applications. Redlands, CA: ESRI Press.

Grant, V. (2014, 07 15). GIS Fire Tech. (M. Escarcega, Interviewer)

Hanford, D. J. (2012, September). facilitiesnet. Retrieved August 15, 2014, from facilitiesnet.com: http://www.facilitiesnet.com/firesafety/article/FacilityManagers-Play-Critical-Role-in-Fire-Safety-Efforts--13469? source=part\#

International Facilities Management Association. (2009). www.ifma.org. Retrieved August 15, 2014, from ifma: http://www.ifma.org/docs/knowledgebase/sfp_whitepaper.pdf

International Facilities Management Association. (2011, May 1). healthyfacilitiesinstitute.com. Retrieved 8 15, 2014, from Healthy Facilities Institute: http://www.healthyfacilitiesinstitute.com/a_108IFMA_Report_Top_10_Trends_Impacting_Facility_Management

Kraak, M. J. (2004). The role of the map in a Web-GIS environment. Journal of Geographical Systems, 6(2).

Longley, P. A., Goodchild, M. F., Maguire, D. J., \& Rhind, D. W. (2011). Geographic Information Systems \& Science. Danvers: John Wiley \& Sons.

Mell, P., \& Grance, T. (2011, September). National Institute of Standards and Technolgy. Retrieved August 23, 2014, from nist.gov: http://csrc.nist.gov/publications/nistpubs/800-145/SP800-145.pdf

Open Geospatial Consortium. (n.d.). Open Geospatial Consortium. Retrieved May 18, 2014, from OGC: http://www.opengeospatial.org/ogc

Perry, S. (2014). SSP Innovations. Retrieved August 23, 2014, from sspinnovations.com: http://www.sspinnovations.com/case-studies/hart-emc-implements-new-flavorarcgis-online-inspections\#.U_ljsWOTKGI

Singleton, A. M., \& Longley, P. A. (2010). Developing Efficient Web-based GIS. University College London, Department of Geography and Centre for Advanced Spatial Analysis. London: University College London. 



\section{Appendix A. Academic Coded Values}

\begin{tabular}{|c|c|c|c|c|}
\hline \multicolumn{5}{|c|}{ Academic Areas } \\
\hline Subtype & Domain Name & Subtype Code & Coded Values & Room Description \\
\hline \multirow[b]{3}{*}{ Classroom } & \multirow[b]{3}{*}{ Classroom } & \multirow[b]{3}{*}{1100} & 1101 & Classroom Type 1 \\
\hline & & & 1102 & Classroom Type 2 \\
\hline & & & 1103 & Classroom Type 3 \\
\hline \multirow[b]{8}{*}{ Community Area } & \multirow[b]{8}{*}{ Community Area } & \multirow[b]{8}{*}{1200} & 1201 & Conversation Area \\
\hline & & & 1202 & Deck Porch \\
\hline & & & 1203 & Living Room \\
\hline & & & 1204 & Lobby \\
\hline & & & 1205 & Lounge \\
\hline & & & 1206 & Reception \\
\hline & & & 1207 & Study Area \\
\hline & & & 1208 & Vending Machines \\
\hline \multirow[b]{4}{*}{ Lab } & \multirow[b]{4}{*}{ Lab } & \multirow[b]{4}{*}{1110} & 1111 & Animal Care \\
\hline & & & 1112 & Computer Lab \\
\hline & & & 1113 & Instructional Lab \\
\hline & & & 1114 & Research Space \\
\hline \multirow[b]{2}{*}{ Lecture Hall } & \multirow[b]{2}{*}{ Lecture Hall } & \multirow[b]{2}{*}{1120} & 1121 & Lecture Hall Type 1 \\
\hline & & & 1122 & Lecture Hall Type 2 \\
\hline
\end{tabular}




\section{Appendix B. Administrative Coded Values}

\begin{tabular}{|c|c|c|c|c|}
\hline \multicolumn{5}{|c|}{ Administrative Areas } \\
\hline Subtype & Domain Name & Subtype Code & $\begin{array}{l}\text { Coded } \\
\text { Values }\end{array}$ & Room Description \\
\hline \multirow[b]{2}{*}{ Conference Room } & \multirow[b]{2}{*}{ Conference Room } & \multirow[b]{2}{*}{1300} & 1301 & Conference Type 1 \\
\hline & & & 1302 & Conference Type 2 \\
\hline \multirow[b]{4}{*}{ Office } & \multirow[b]{4}{*}{ Office } & \multirow[b]{4}{*}{1310} & 1311 & Faculty \\
\hline & & & 1312 & Staff \\
\hline & & & 1314 & Administrative \\
\hline & & & 1315 & Student \\
\hline
\end{tabular}




\section{Appendix C. Other Areas Coded Values}

\begin{tabular}{|c|c|c|c|c|}
\hline \multicolumn{5}{|c|}{ Other Areas } \\
\hline Subtype & Domain Name & Subtype Code & Coded Values & Room Description \\
\hline \multirow[b]{3}{*}{ Bathroom } & \multirow[b]{3}{*}{ Bathroom } & 1000 & 1001 & Men \\
\hline & & & 1002 & Gender Neutral \\
\hline & & & 1003 & Women \\
\hline Corridor & Corridors & 900 & 901 & Corridor \\
\hline Custodial & \multirow[b]{3}{*}{ Operations } & \multirow[b]{3}{*}{1400} & 1437 & Custodial \\
\hline Elevator & & & 1435 & Elevator \\
\hline $\begin{array}{l}\text { Elevator } \\
\text { Equipment }\end{array}$ & & & 1436 & Elevator Equipment \\
\hline & \multirow[b]{3}{*}{ Kitchen } & \multirow[b]{3}{*}{1010} & 1011 & Kitchen Type 1 \\
\hline Kitchen & & & 1012 & Kitchen Type 2 \\
\hline Laundry & & & 1021 & Laundry \\
\hline $\begin{array}{l}\text { Network } \\
\text { Equipment }\end{array}$ & Operations & 1400 & 1400 & Network Equipment \\
\hline \multirow[b]{4}{*}{ Office } & \multirow[b]{4}{*}{ Office } & \multirow[b]{4}{*}{1310} & 1311 & Faculty \\
\hline & & & 1312 & Staff \\
\hline & & & 1314 & Administrative \\
\hline & & & 1315 & Student \\
\hline Server & Operations & 1400 & 1411 & Server Room \\
\hline
\end{tabular}




\begin{tabular}{|c|c|c|c|c|}
\hline \multicolumn{5}{|c|}{ Other Areas } \\
\hline Subtype & Domain Name & Subtype Code & Coded Values & Room Description \\
\hline \multirow[t]{2}{*}{ Stairs } & \multirow[b]{2}{*}{ Corridors } & \multirow[b]{2}{*}{900} & 902 & Stairs Interior \\
\hline & & & 903 & Stairs Exterior \\
\hline \multirow[b]{4}{*}{ Storage } & \multirow[b]{4}{*}{ Storage } & \multirow[b]{4}{*}{1320} & 1321 & Office Supplies \\
\hline & & & 1322 & Teaching Supplies \\
\hline & & & 1323 & Instructional Equipment \\
\hline & & & 1325 & Storage Residential \\
\hline \multirow[b]{3}{*}{ Utility } & \multirow[b]{3}{*}{ Utility } & \multirow[b]{3}{*}{1420} & 1421 & Electrical \\
\hline & & & 1422 & Mechanical \\
\hline & & & 1423 & Telecom \\
\hline Roof Access & & & 1434 & Rood Access \\
\hline
\end{tabular}


